\title{
miR-26 suppresses adipocyte progenitor differentiation and fat production by targeting Fbxl19
}

\author{
Asha Acharya, ${ }^{1}$ Daniel C. Berry, ${ }^{2}$ He Zhang, ${ }^{3,4}$ Yuwei Jiang, ${ }^{5}$ Benjamin T. Jones, ${ }^{1}$ Robert E. Hammer, ${ }^{6}$ \\ Jonathan M. Graff, ${ }^{1,7}$ and Joshua T. Mendell ${ }^{1,8,9,10}$ \\ ${ }^{1}$ Department of Molecular Biology, University of Texas Southwestern Medical Center, Dallas, Texas 75390 , USA; ${ }^{2}$ Division of \\ Nutritional Sciences, Cornell University, Ithaca, New York 14853, USA; ${ }^{3}$ Quantitative Biomedical Research Center, University of \\ Texas Southwestern Medical Center, Dallas, Texas 75390, USA; ${ }^{4}$ Department of Clinical Sciences, University of Texas \\ Southwestern Medical Center, Dallas, Texas 75390, USA; ${ }^{5}$ Department of Physiology and Biophysics, University of Illinois at \\ Chicago, Chicago, Illinois 60612, USA; ${ }^{6}$ Department of Biochemistry, University of Texas Southwestern Medical Center, Dallas, \\ Texas 75390, USA ${ }^{7}$ Department of Internal Medicine, Division of Endocrinology, University of Texas Southwestern Medical \\ Center, Dallas, Texas 75390, USA; ${ }^{8}$ Harold C. Simmons Comprehensive Cancer Center, University of Texas Southwestern Medical \\ Center, Dallas, Texas 75390, USA; ${ }^{9}$ Hamon Center for Regenerative Science and Medicine, University of Texas Southwestern \\ Medical Center, Dallas, Texas 75390, USA; ${ }^{10}$ Howard Hughes Medical Institute, University of Texas Southwestern Medical \\ Center, Dallas, Texas 75390, USA
}

Fat storage in adult mammals is a highly regulated process that involves the mobilization of adipocyte progenitor cells (APCs) that differentiate to produce new adipocytes. Here we report a role for the broadly conserved miR-26 family of microRNAs (miR-26a-1, miR-26a-2, and miR-26b) as major regulators of APC differentiation and adipose tissue mass. Deletion of all miR-26-encoding loci in mice resulted in a dramatic expansion of adipose tissue in adult animals fed normal chow. Conversely, transgenic overexpression of miR-26a protected mice from high-fat dietinduced obesity. These effects were attributable to a cell-autonomous function of miR-26 as a potent inhibitor of APC differentiation. miR-26 blocks adipogenesis, at least in part, by repressing expression of Fbxl19, a conserved miR-26 target without a previously known role in adipocyte biology that encodes a component of SCF-type E3 ubiquitin ligase complexes. These findings have therefore revealed a novel pathway that plays a critical role in regulating adipose tissue formation in vivo and suggest new potential therapeutic targets for obesity and related disorders.

[Keywords: adipocyte progenitor cell; adipogenesis; Fbxl19; obesity; white adipose tissue; miR-26; microRNA]

Supplemental material is available for this article.

Received May 17, 2019; revised version accepted August 13, 2019.

MicroRNAs (miRNAs) comprise a class of diverse $\sim 21$ - to 23-nt noncoding RNAs that were first discovered in C. elegans and subsequently found to regulate the expression of a large fraction of metazoan mRNAs (Krol et al. 2010; Bartel 2018). Encoded either within the introns of proteincoding genes or transcribed under the control of their own promoters, miRNAs are produced through a defined processing pathway involving sequential endonucleasemediated cleavages by the RNase III enzymes DROSHA and DICER (Ha and Kim 2014). After maturation, miRNAs are loaded into a member of the Argonaute (AGO) family of proteins, which they guide to sites of partial complementarity predominantly within the 3' UTRs of target mRNAs, resulting in accelerated deadenylation, increased turnover, and reduced translation (Jonas and Izaurralde 2015; Gebert and MacRae 2019). Through the

Corresponding author: joshua.mendell@utsouthwestern.edu Article published online ahead of print. Article and publication date are online at http://www.genesdev.org/cgi/doi/10.1101/gad.328955.119. regulation of extensive target repertoires, miRNAs broadly impact mammalian development and physiology, while miRNA dysfunction has been causatively linked to several human diseases including cancer and cardiovascular disease (Bartel 2009; Mendell and Olson 2012).

Obesity, and associated metabolic abnormalities such as Type 2 diabetes represent a growing public health crisis in Western nations due to the association with cardiovascular disease and all-cause mortality (Martin et al. 2015). Several studies have uncovered important roles for miRNAs in regulating obesity-associated metabolism due to their ability to modulate cellular responses to dietary and metabolic cues such as cholesterol, glucose, and insulin (Najafi-Shoushtari et al. 2010; Rayner et al. 2010;

(C) 2019 Acharya et al. This article is distributed exclusively by Cold Spring Harbor Laboratory Press for the first six months after the full-issue publication date (see http://genesdev.cshlp.org/site/misc/terms.xhtml). After six months, it is available under a Creative Commons License (Attribution-NonCommercial 4.0 International), as described at http://creativecommons.org/licenses/by-nc/4.0/. 
Dooley et al. 2016). A fundamental characteristic of obesity is the uncontrolled expansion and accumulation of white adipose tissue (WAT) (Berry et al. 2013). In addition to storing energy during times of caloric surplus, WAT functions as a critical node in the regulation of systemic metabolism by secreting signaling proteins and lipids that influence key physiologic responses such as appetite, glucose homeostasis, and immune responses (Deng and Scherer 2010; Blüher 2014). Under obesogenic conditions, pre-existing adipocytes expand to accommodate excess nutrients in the form of triglycerides. Additionally, new adipocytes are generated from a proliferative population of adipocyte progenitor cells (APCs) that localize to the WAT vasculature where they resemble mural cells. APCs can be distinguished from other nonadipogenic mural cells due to their expression of the master regulator of adipogenesis, peroxisome proliferator-activated receptor $\gamma$ (PPAR 2) (Tontonoz et al. 1994; Wu et al. 1999; Rosen and MacDougald 2006; Tontonoz and Spiegelman 2008). Genome-wide profiling has revealed that PPAR $\gamma 2$ occupies the promoters of numerous adipogenic genes to drive adipogenesis and terminal differentiation (Lefterova et al. 2008; Nielsen et al. 2008). While the transcriptional hierarchy that drives APC mobilization and adipogenesis has been extensively characterized, the importance of miRNA-mediated regulation in this process remains unclear. Further insight into the functions of miRNAs within this lineage would illuminate our understanding of adipocyte development and function, and might reveal new therapeutic approaches to counteract obesity.

The miR-26 family (miR-26a-1, miR-26a-2, and miR$26 \mathrm{~b}$ in mammals) represents a highly conserved family of vertebrate miRNAs that have been implicated in a broad array of developmental and physiological functions, including neuronal differentiation (Dill et al. 2012), muscle development (Dey et al. 2012; Icli et al. 2013), and hepatic glucose and lipid metabolism (Fu et al. 2015). In addition, miR-26 family members have been implicated as tumor suppressors in multiple types of cancer, including hepatocellular carcinoma (Ji et al. 2009; Kota et al. 2009) and colorectal cancer (Zeitels et al. 2014). Despite the extensive prior investigation of the functions of these miRNAs, however, our understanding of their importance in mammalian development and physiology has been limited by the difficulty in studying the consequences of miR26 loss-of-function in vivo. The three ubiquitously expressed and likely redundant mammalian miR-26 family members are produced from unlinked loci, which has deterred previous efforts to produce complete miR-26 knockout mice.

In this study, we report the application of CRISPR/ Cas9-mediated genome editing to generate mice lacking all miR-26 family members. Although analysis of these animals showed that these miRNAs are dispensable for overtly normal development, a critical role for miR-26 as a physiologic suppressor of adult adipogenesis was unexpectedly revealed. miR-26 triple knockout (TKO) mice exhibit excessive fat production due to precocious differentiation of APCs. Furthermore, we provide evidence that regulation of APC differentiation by miR-26 is medi- ated, at least in part, by repression of Fbxl19, a novel miR26 target that encodes a component of SCF family E3 ubiquitin ligase complexes. Together, these results reveal a new pathway that regulates adipogenesis and uncover potential therapeutic targets for obesity.

\section{Results}

Global loss of miR-26 results in excess body fat and dyslipidemia

To investigate the role of miR-26 in mammalian physiology in vivo, CRISPR/Cas9-mediated genome editing was used to generate mice lacking all miR-26 family members. In both mouse and human genomes, all three miR-26 family members reside in the introns of genes coding for Carboxy-terminal domain RNA polymerase II polypeptide A small phosphatase (CTDSP) proteins (Supplemental Fig. S1A), an organization conserved to zebrafish (Dill et al. 2012). Due to the nearly identical sequences of miR-26a and miR-26b, as well as their broad expression in mouse tissues (Fig. 1A; Supplemental Fig. S1B,C), these miRNAs most likely function redundantly. We therefore designed single guide RNAs (sgRNAs) targeting each miRNA, taking advantage of a protospacer adjacent motif (PAM) near the seed sequence (Fig. 1A). Despite a high degree of sequence similarity, the individual sgRNAs did not exhibit detectable cross-targeting of the other miR-26 loci when introduced into embryonic stem (ES) cells (Supplemental Fig. S2A).

miR-26-targeting sgRNAs, together with Cas9 mRNA, were co-injected into fertilized C57BL/6 oocytes, resulting in the generation of insertion/deletion mutations at all three genomic loci (miR-26a-1, miR-26a-2, and miR-26b). Alleles with small deletions that removed the $5^{\prime}$ end of each miRNA, including the seed sequences (Fig. 1A), were propagated and combined by standard breeding to yield the total knockout, hereafter referred to as miR-26 triple-knockout (TKO) mice. Initial analyses revealed that $\mathrm{miR}-26-\mathrm{TKO}$ mice were born at the expected Mendelian ratio, were fertile, and displayed no overt phenotype at weaning (Supplemental Fig. S2B,C; data not shown). Quantitative RT-PCR (qRT-PCR) confirmed the loss of miR-26a and miR-26b expression in multiple tissues (Supplemental Fig. S2D,E). Additionally, the deletion mutations did not affect expression of the miR-26 host transcripts (Supplemental Fig. S2F-H).

A careful examination of young adult mice revealed that while most tissues appeared indistinguishable between wild-type and miR-26-TKO mice, both male and female knockout animals exhibited an approximately twofold to threefold increase in white adipose tissue (WAT) (Fig. 1B,C; Supplemental Fig. S3A). An intermediate phenotype was observed in mice lacking five out of six miR-26 alleles (hereafter referred to as 5/6-KO mice, which harbor only a single intact allele of miR-26a-2). Histologic analysis of WAT demonstrated an absence of adipocyte hypertrophy in TKO mice (Fig. 1D, top panels), suggesting that the expansion of fat depots was a consequence of excessive production of adipocytes. 
A

miR-26a

loop

miR-26a*

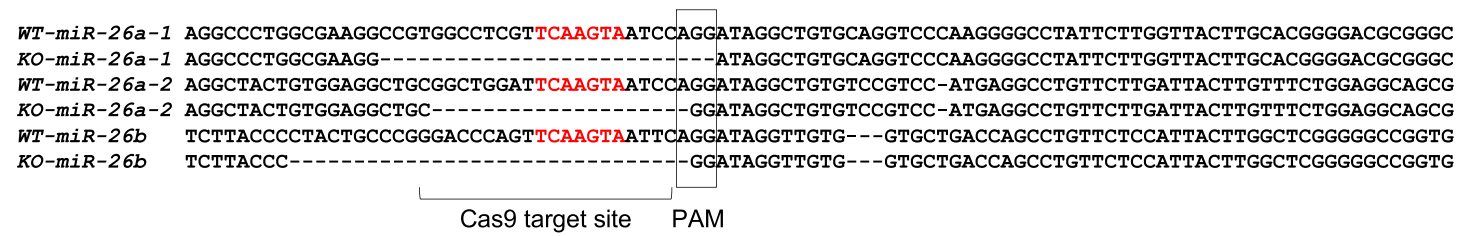

B

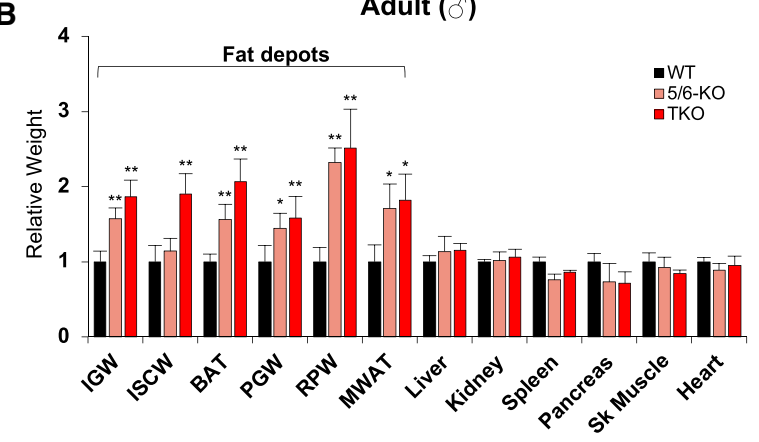

c

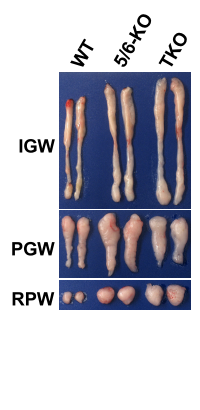

D

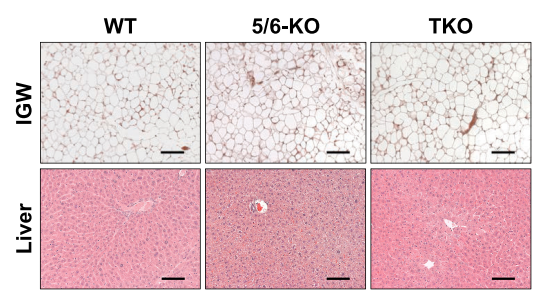

E

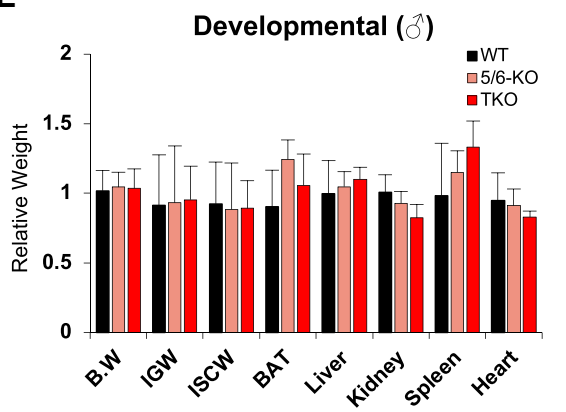

F

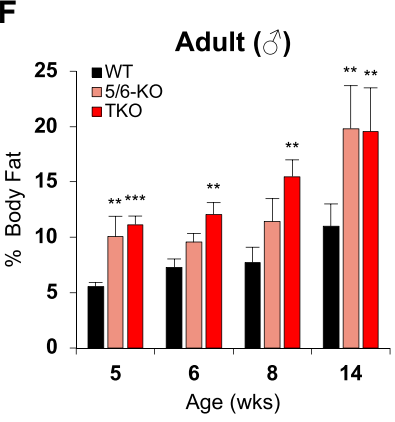

G

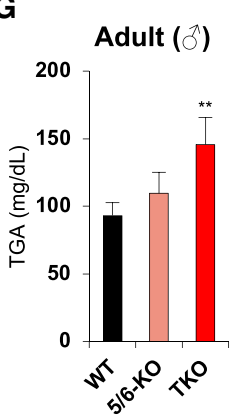

H

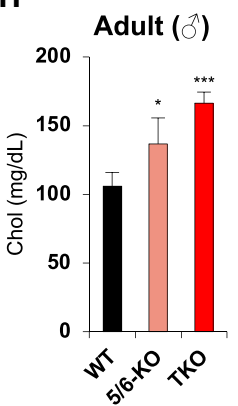

Figure 1. miR-26-TKO mice have excess body fat and dyslipidemia. (A) Sequences of mouse miR-26a-1, miR-26a-2, and miR-26b genomic loci and deletion alleles generated using CRISPR/Cas9. Protospacer adjacent motif (boxed rectangle), miRNA seed region (red) and sgRNA sequence used for targeting (Cas9 targeting site) are shown. (B) Relative weights of isolated fat depots and major organs from 3mo-old male mice of the indicated genotypes fed standard chow, normalized to wild type ( $n=6$ mice per genotype). 5/6-KO denotes mice with five of the six miR-26 alleles knocked out with only one wild-type copy of miR-26a-2 intact. (TKO) Triple knockout mice. Fat depots: (IGW) Iguinal; (ISCW) interscapular; (PGW) perigonadal; (RPW) retroperitoneal; (MWAT) mesenteric; (BAT) brown adipose tissue. $(C)$ Representative whole-mount images of subcutaneous and visceral white fat depots of mice from $B$. (D) Representative H\&E stained sections of IGW (top panels) and liver (bottom panels) from mice of the indicated genotypes. Scale bars, $100 \mu M$. (E) Relative weights of isolated fat depots and major organs from postnatal day 10 male mice $(n=4-6$ mice per genotype). No significant differences were noted at this time point. $(F)$ Fat content of male mice at indicated ages measured by whole body NMR $(n=6$ mice per genotype, per timepoint). $(G, H)$ Serum triglycerides $(G)$ and cholesterol $(H)$ in 3-mo-old male mice $(n=6$ mice per genotype). For panels $B$ and $E-$ $H$, data are represented as mean \pm SD. $\left(^{*}\right) P<0.05 ;\left(^{* *}\right) P<0.01 ;\left({ }^{* * *}\right) P<0.001$, calculated using two-tailed $t$-test.

Adipocytes are generated from progenitor populations through distinct developmental and adult phases of adipogenesis. While developmental progenitors are primarily responsible for producing a defined number of adipocytes during embryogenesis, adult adipocyte progenitors respond to a variety of environmental and dietary cues such as high-fat diet to produce new adipocytes when increased energy storage is required (Jiang et al. 2014; Wang et al. 2015). In order to determine which phase of adipogenesis is responsible for the increase in WAT in miR-26-TKOs, we first analyzed mice at postnatal day 10 (P10), a time-point at which WAT is predominantly derived from developmental progenitors. No difference in WAT mass between wild-type and TKO mice was detectable at this age (Fig. 1E; Supplemental Fig. S3B). In contrast, young adult TKO mice, starting as early as $5 \mathrm{wk}$ of age, exhibited a clear and progressive increase in whole body fat content (Fig. 1F; Supplemental Fig. S3C), suggesting excessive activation of the adult adipogenesis program despite a diet of normal mouse chow. Moreover, serum analysis indicated that TKO mice were dyslipidemic, with elevated levels of serum triglycerides (Fig. 1G; Supplemental Fig. S3D) and cholesterol (Fig. 1H; Supplemental Fig. S3E). Despite producing excess WAT, TKO 
mice did not exhibit liver steatosis (Fig. 1D, bottom panels), glucose intolerance (Supplemental Fig. S3F-I), or an increase in overall body weight (Supplemental Fig. S3J, K). Furthermore, metabolic cage studies demonstrated that wild-type and TKO mice had similar food intake, physical activity, and energy consumption, as indicated by oxygen consumption and carbon dioxide production (Supplemental Fig. S4A-D). Thus, these data support a previously unrecognized role for $\mathrm{miR}-26$ as a physiologic suppressor of adult adipogenesis.

\section{miR-26a overexpression protects mice from diet-induced obesity}

Given the significant expansion of WAT in miR-26-TKO mice, we hypothesized that this miRNA family may function as a rheostat to control fat production in adult animals. To further test this model, we took advantage of a previously described transgenic mouse line with doxycycline (dox)-inducible miR-26a expression (Fig. 2A, M2rtTA; eGFP.miR-26a mice) (Zeitels et al. 2014) to determine whether enforced expression of this miRNA could suppress WAT expansion in adult mice. High fat diet (HFD) is a potent stimulant of APC differentiation and resultant de novo adipocyte production (Joe et al. 2009; Wang et al. 2013b; Jeffery et al. 2015; Vishvanath et al. 2016). As expected, control mice (M2rtTA only) fed a HFD for 12 wk exhibited significant weight gain and an overall total body fat content close to $40 \%$ (Fig. $2 \mathrm{~B}, \mathrm{C})$. In contrast, mice with global overexpression of miR-26a were strongly resistant to weight gain and HFD-induced WAT expansion (Fig. 2B-E). Notably, despite a substantial reduction in total fat mass, hepatic lipid storage was not altered in HFD-fed miR-26-overexpressing mice (Fig. 2D; data not shown). We also note that an apparent decrease in pancreas weight in miR-26a overexpressing animals (Fig. 2D) was most likely due to a reduction in contaminating visceral adipose tissue in dissected pancreata from these mice. In addition to lower overall body fat, HFD-fed miR-26a transgenic mice exhibited lower serum glucose and lipid levels compared with controls (Fig. 2F-I). Thus, enforced miR-26a expression protected against the adipogenic and metabolic effects of HFD.
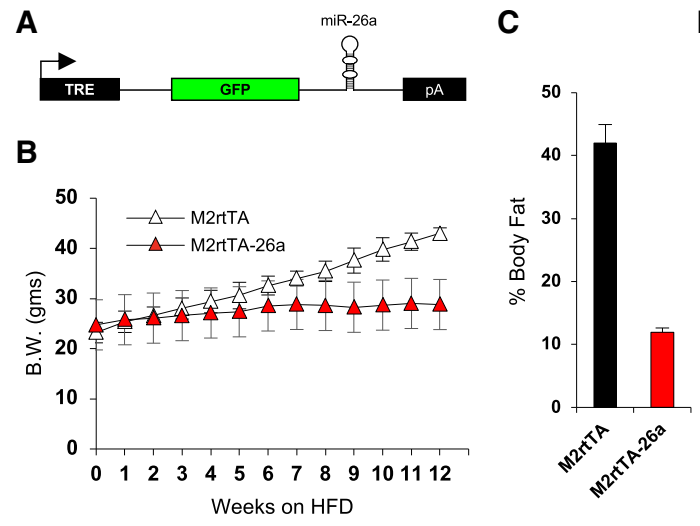

D
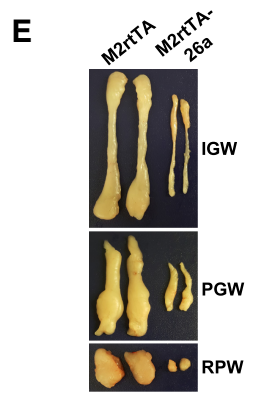

$\mathbf{F}$

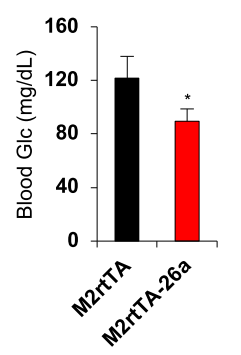

G

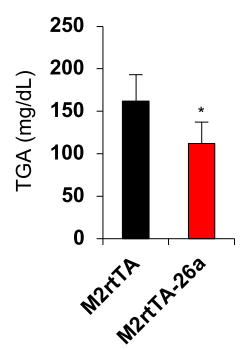

H

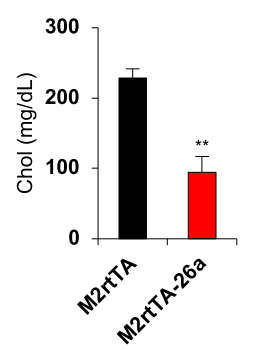

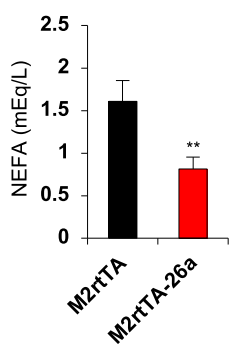

Figure 2. Global overexpression of miR-26a protects mice from HFD-induced obesity. $(A)$ Schematic of the dox-inducible mR-26a transgene (eGFP.miR-26a) (Zeitels et al. 2014). TRE, Tetracycline-response element; pA, poly(A) signal. (B) Body weight of double transgenic (M2rtTA; eGFP.miR-26a, abbreviated M2rtTA-26a) and control (M2rtTA only, abbreviated M2rtTA) male mice ( $n=6-8$ per genotype) on dox and HFD for $12 \mathrm{wk}$. M2rtTA-26a and M2rtTA male transgenic mice were switched to dox-containing water $(2 \mathrm{mg} / \mathrm{mL})$ at $6 \mathrm{wk}$ of age. Two weeks later, HFD was initiated and body weight was recorded weekly. (C) Whole body fat content of mice in $B$ after 12 wk on HFD analyzed by NMR. $(D)$ Relative weights of isolated fat depots and major organs from mice from $B$ after 12 wk on HFD. (E) Representative images of isolated subcutaneous (IGW) and visceral (PGW and RPW) fat depots from mice of the indicated genotypes from $B$. $(F-I)$ Blood glucose $(F)$, serum triglycerides $(G)$, cholesterol $(H)$, and nonesterified free fatty acids $(I)$ in mice from $B$ after 12 wk on HFD. Data presented in $B-I$ are part of the same experiment and representative of three independent experiments. Data represented as mean $\pm \mathrm{SD} .\left(^{*}\right) P<0.05$; $(* *) P<0.01 ;(* * *) P<0.001$, calculated using two-tailed $t$-test. 
To test whether miR-26a overexpression could also protect mice from weight gain on normal chow, control and transgenic mice were analyzed after 1 yr of dox administration. Similar to the results obtained after feeding a HFD, miR-26a transgenic mice on normal chow gained less weight, exhibited less total body fat, and displayed dramatically smaller fat depots than control animals (Supplemental Fig. S5A-E). Together with the loss-of-function studies, these results demonstrate that miR-26 levels dictate the extent of fat production in adult mice.

\section{miR-26 regulates adipogenic differentiation in vitro}

These initial studies used animal models with global miR26 loss- and gain-of-function. In order to investigate whether this miRNA family functions intrinsically within the adipocyte lineage to control adipogenesis, multiple experimental strategies were pursued. First, we confirmed that miR-26 is expressed within APCs. The stromal vascular fraction (SVF) of WAT, obtained by enzymatic disso- ciation of adipose depots that have been depleted of mature adipocytes, constitutes a heterogenous mixture of mural cells, endothelial cells, immune cells, and APCs. Fluorescence-activated cell sorting (FACS) was used to isolate APCs from the SVF of Adipotrak mice (Pparg-tTA; TRE-H2B-GFP), in which Pparg-expressing APCs are labeled with GFP (Tang et al. 2008). miR-26a and miR-26b expression was readily detectable in APCs and modestly enriched relative to the GFP-negative SVF population (Supplemental Fig. S6A,B).

We next examined the consequences of modulation of miR-26 activity on adipogenesis using an in vitro SVF differentiation assay (Fig. 3A). To avoid systemic effects of miR-26 loss-of-function from influencing APC numbers or behavior prior to in vitro culture, SVF cultures were established from wild-type mice and miR-26 was inhibited after SVF isolation using locked nucleic acid (LNA) antisense oligonucleotides (Fig. 3B). Acute miR-26 inhibition resulted in a robust induction of adipogenic gene expression (Fig. 3C) and adipocyte differentiation (Fig. 3D) in

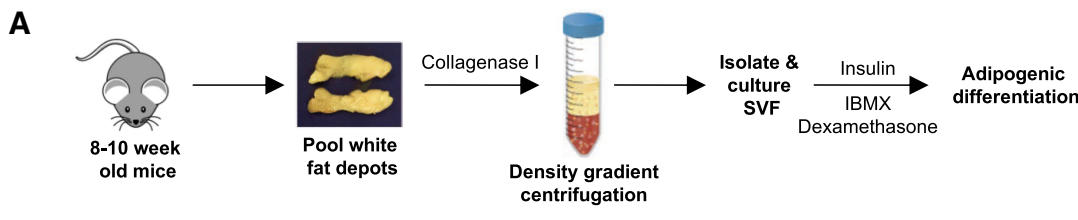

B

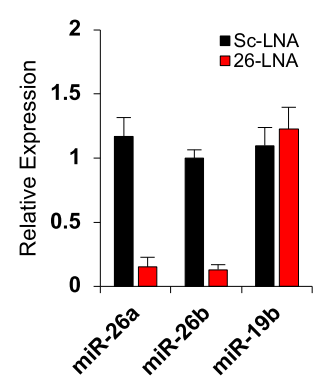

C
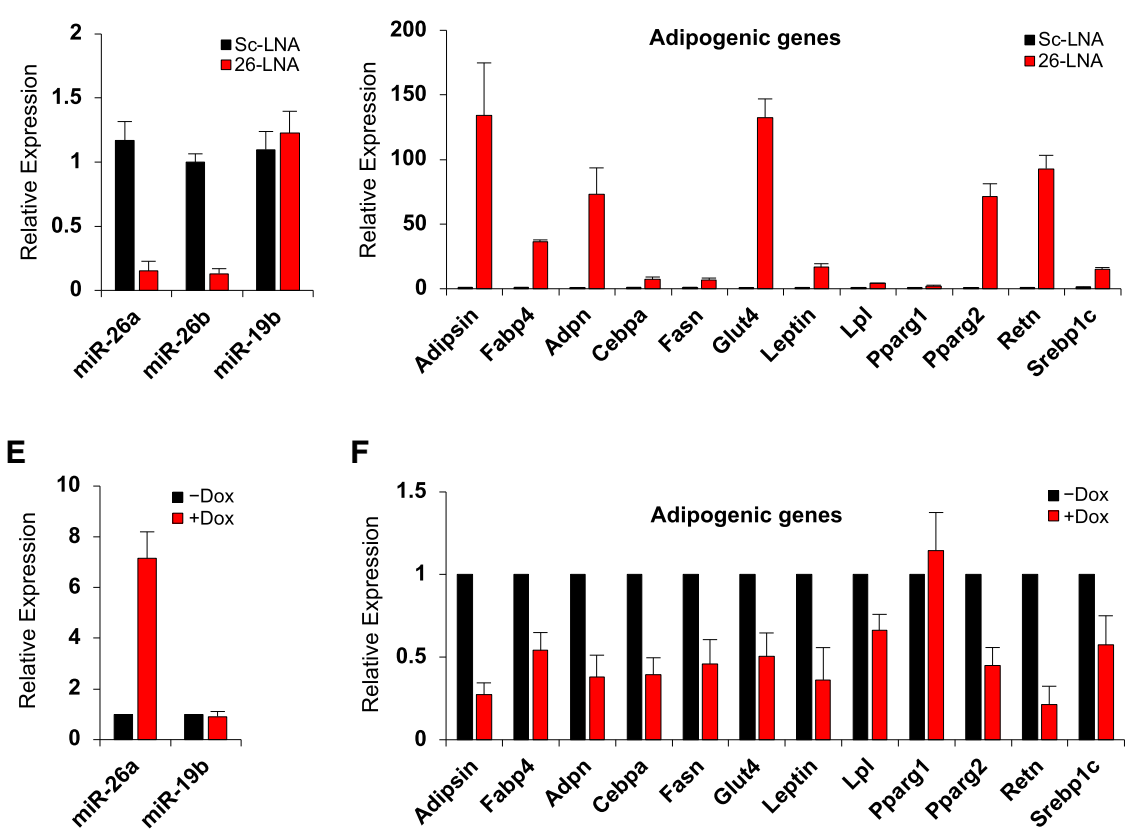

$\mathbf{F}$

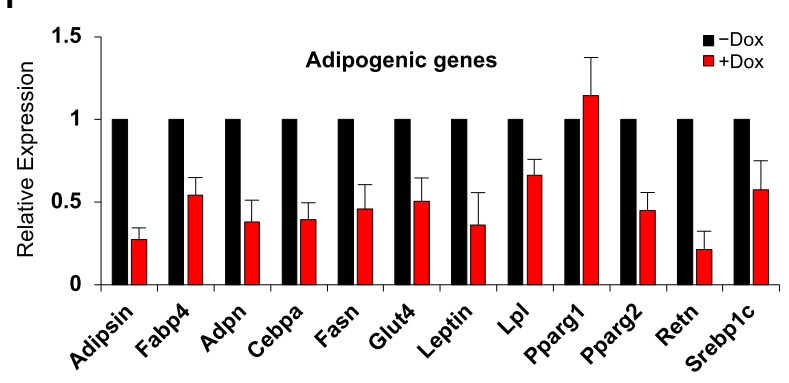

D

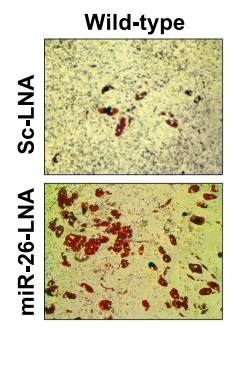

G

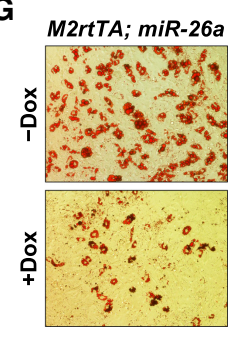

Figure 3. miR-26 regulates adipogenesis in vitro. $(A)$ Schematic of isolation and in vitro differentiation of stromal vascular fraction (SVF) from pooled fat depots of adult mice. (B) qRT-PCR analysis of mature miR-26a, miR-26b, and miR-19b (an unrelated control miRNA) in wild-type SVF cultures transfected with miR-26 LNA antisense inhibitors (26-LNA) or scrambled control LNA oligonucleotides (Sc-LNA). $n=3$ biological replicates per condition. $(C)$ qRT-PCR analysis of adipogenic gene expression following in vitro differentiation of miR-26 LNA-transfected SVF cultures from $B$, relative to scrambled control transfected SVFs. $(D)$ Representative images of Oil Red O-stained SVF cultures from B. (E) qRT-PCR analysis of miR-26a or miR-19b levels in SVFs derived from M2rtTA; eGFP.miR-26a transgenic mice, cultured with or without dox $(1 \mu \mathrm{g} / \mathrm{mL})$ for $4 \mathrm{~d}$ prior to induction of differentiation. $n=3$ biological replicates per condition. $(F)$ qRT-PCR analysis of adipogenic gene expression following in vitro differentiation of dox-treated SVF cultures from $E$, relative to untreated cultures. $(G)$ Representative images of Oil Red O-stained SVF cultures from $E$. Data represented as mean \pm SD. 
this system. Increased adipogenesis was also observed in SVF cultures derived from young miR-26-TKO mice relative to cultures derived from age- and sex-matched wild-type animals (Supplemental Fig. S6C-E). Conversely, doxycycline-induced overexpression of miR-26a in SVF cultures from M2rtTA; eGFP.miR-26a mice (Fig. 2A) strongly inhibited adipogenesis (Fig. 3E-G), while doxycycline treatment of SVFs obtained from M2rtTA control mice had no antiadipogenic effect (Supplemental Fig. S6FH). Together, these data support a direct role for miR-26 as a suppressor of adipogenesis via its activity within the adipocyte lineage.
miR-26a expression in adult $S M A^{+} A P C s$ confers resistance to $H F D$-induced obesity

To further assess whether miR-26 expression within adipocyte progenitors is sufficient to suppress adult adipogenesis in vivo, we utilized a miR-26a transgene that is activated by both dox treatment and Cre expression (Fig. 4A, M2rtTA; LSL.eGFP.miR-26a mice) (Zeitels et al. 2014). Adult APCs reside in the perivascular niche of fat depots and resemble pericytes or mural cells (Rodeheffer et al. 2008; Tang et al. 2008; Gupta et al. 2012; Berry and Rodeheffer 2013). A smooth muscle actin (SMA)-
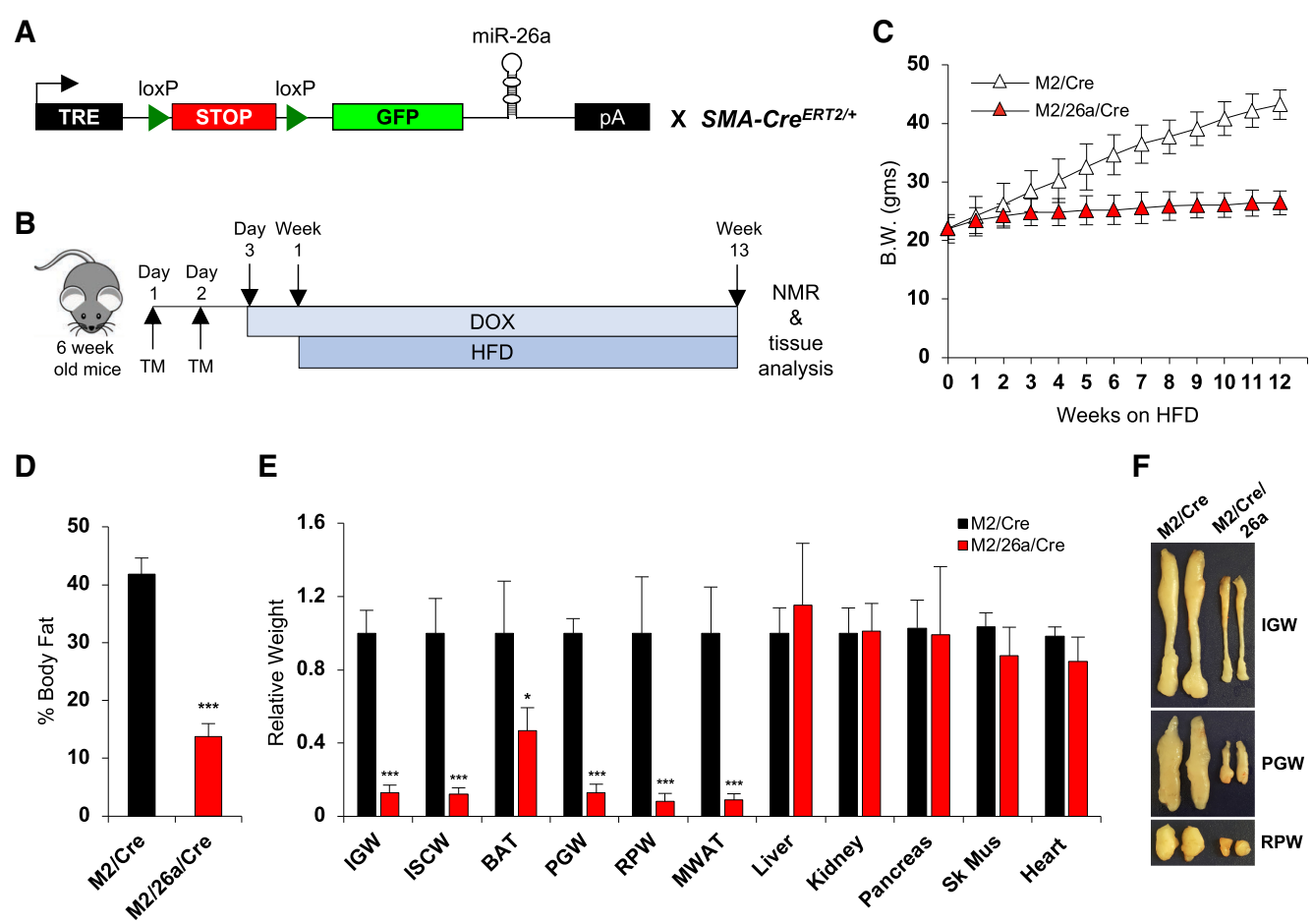

E
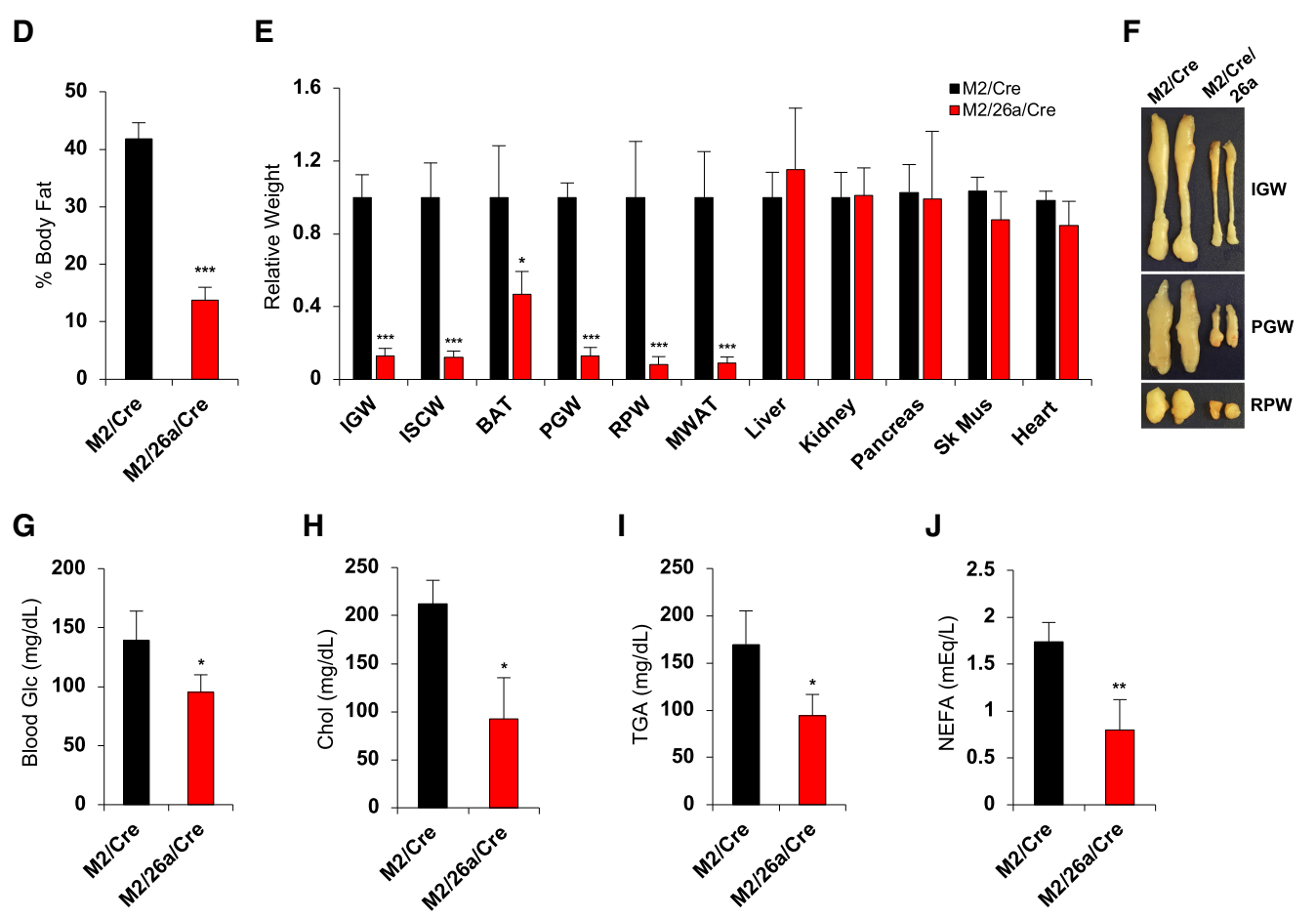

Figure 4. Overexpression of miR-26a in adult APCs prevents HFD-induced obesity. (A) Schematic of the dox-and Cre-inducible miR-26a transgene (LSL.eGFP.miR-26a) crossed to tamoxifen-inducible SMA-Cre ${ }^{E R T 2 /+}$ for overexpression of miR-26a in adult APCs. (B) Experimental time course. Tamoxifen (TM) was administered to 6-wk-old M2rtTA; LSL.eGFP.miR-26a; SMA-Cre ${ }^{E R T 2 /+}$ (M2/26a/Cre) and control M2rtTA; SMA-Cre $e^{E R T 2 /+}(M 2 / C r e)$ mice, followed by administration of dox to activate miR-26 expression in the APC lineage. Mice were then fed a HFD for $12 \mathrm{wk}$. (C) Body weight of control (M2/Cre) and transgenic (M2/Cre/26a) mice on HFD ( $n=6-8$ mice per genotype) recorded weekly. $(D)$ Whole body fat content of mice from $C$ measured by NMR after 12 wk on HFD. (E) Relative weights of isolated fat depots and major organs of mice from $C$ after $12 \mathrm{wk}$ on HFD. $(F)$ Representative whole-mount images of subcutaneous IGW and visceral PGW and RPW fat depots from mice from $C$ after 12 wk on HFD. $(G-J)$ Blood glucose $(G)$, serum cholesterol $(H)$, triglycerides $(I)$, and nonesterified fatty acids $(J)$ from mice from $C$ after 12 wk on HFD. Data represented as mean \pm SD. $\left({ }^{*}\right) P<0.05 ;\left({ }^{* *}\right) P<0.01 ;\left(^{* * *}\right) P<0.001$ calculated using two-tailed $t$-test. 
Cre ${ }^{\text {ERT2/+ }}$ allele, which is expressed in adult APCs but not mature adipocytes (Wendling et al. 2009; Jiang et al. 2014), was used to activate the miR-26 transgene within this lineage. Transgenic mice (M2rtTA; LSL.eGFP.miR-26a; $S M A-C r e^{E R T 2 /+}$ ) were administered tamoxifen to activate Cre-recombinase, then treated with dox to turn on miR26a expression in APCs (Fig. 4B). Mice were subsequently fed a HFD for 12 wk. Overexpression of miR-26a in the $\mathrm{SMA}^{+} \mathrm{APC}$ lineage conferred strong protection against HFD-induced weight gain (Fig. 4C). Relative to control mice, miR-26a overexpressing mice had lower total body fat, smaller fat depots, and reduced serum glucose and lipids (Fig. 4D-J). These data further support a cell-autonomous role for miR-26 in suppressing adult adipogenesis, although it remains possible that additional effects of miR-26 overexpression on food intake, nutrient absorption, or energy expenditure also contribute to protection from weight gain.

\section{Precocious differentiation of APCs in miR-26-TKOs}

To definitively assess whether loss of miR-26 triggers adipogenic differentiation in vivo, we performed a lineage tracing experiment to monitor the differentiation of APCs to mature adipocytes. To indelibly label adult APCs and their descendants, we utilized SMA-Cre $e^{E R T 2 /+}$ in combination with a reporter allele that produces tdTomato when coexpressed with Cre $\left(R 26 R^{t d T /+}\right)$ (Fig. 5A; Wendling et al. 2009). Cre recombinase was activated at P25 by tamoxifen administration and the fate of labeled APCs was followed over time to determine the extent to which they gave rise to mature adipocytes (Fig. 5B). As expected, analysis of adipose depots $2 \mathrm{~d}$ after Cre activation resulted in robust labeling of the vasculature, most likely representing smooth muscle and perivascular cells including APCs (Fig. 5C, top panels). Importantly, at this time point, no reporter expression was observed in mature adipocytes. Similarly, very few labeled adipocytes were present $>3$-wk later at P50 in wild-type mice (Fig. 5C, bottom panels; Supplemental Fig. S7A). In contrast, extensive labeling of mature adipocytes was apparent at P50 in miR26-TKO mice. To determine whether this increase in APC-derived adipocytes could be the result of an expansion of the APC population in miR-26-TKO mice, we quantified the numbers of $\mathrm{tdT}^{+}$; Sca- $1^{+}$cells (Sca-1 distinguishes APCs from smooth muscle) in fat depots from tamoxifen-treated animals using flow cytometry. These experiments confirmed that loss of miR-26 does not result in an overt increase in the overall number of APCs (Supplemental Fig. S7B). Together, these data strongly support the conclusion that miR-26 is necessary to suppress precocious differentiation of APCs into mature adipocytes.

To determine the physiologic consequences of precocious APC differentiation in miR-26-deficient animals, we next examined cohorts of wild-type and miR-26-TKO mice fed a HFD. Young (6-wk-old) wild-type and miR26-TKO mice exhibited comparable weight gain over a 12-wk period on a HFD (Fig. 5D,E). Surprisingly, however, older miR-26-TKO mice gained significantly less weight and accumulated significantly less body fat than age- matched controls (Fig. 5F-I). These data suggest that excessive differentiation of APCs in young miR-26-deficient mice results in a depletion of the APC pool, ultimately resulting in defective production of new adipocytes in response to caloric excess later in life.

\section{Fbxl19 is a novel miR-26 target that promotes adipogenesis}

To investigate the mechanisms through which miR-26 suppresses adult adipogenesis, we performed RNA-seq on primary SVF cultures from wild-type or miR-26-TKO mice, or M2rtTA; eGFP.miR-26a mice with or without dox treatment (Fig. 6A). From these data, we sought genes that (1) were up-regulated at least 1.5-fold in miR-26-TKO cells, (2) were down-regulated at least 1.5 -fold in dox-treated M2rtTA; eGFP.miR-26a cells, and (3) had multiple conserved predicted miR-26 binding sites according to Targetscan7.2 (Agarwal et al. 2015). Two genes, which to our knowledge have not previously been implicated in the regulation of adipogenesis, fulfilled these criteria: F-box and leucine rich repeat protein 19 (Fbxl19) and STE20 related adaptor $\beta$ (StradB). FBXL19 is a component of Skp1-Cullin-F-box E3 ubiquitin ligase complexes and has been shown to trigger proteasome-mediated degradation of protein targets involved in inflammation, apoptosis, and cell migration (Zhao et al. 2012, 2013; Dong et al. 2014). More recently, a role for FBXL19 in the epigenetic activation of lineage-specific genes during embryonic stem cell differentiation was uncovered (Lee et al. 2017; Dimitrova et al. 2018). STRADB is a pseudokinase that regulates activity of the LKB1 kinase (Boudeau et al. 2003). Up-regulation of Fbxl19 and StradB in miR-26TKO SVF cultures or down-regulation in dox-treated M2rtTA; eGFP.miR-26a cultures, was confirmed by qRT-PCR (Fig. 6B,C; Supplemental Fig. S7C,D). An increase in FBXL19 protein in miR-26-TKO cultures was further documented by Western blotting (Fig. 6D).

To directly assess the role of Fbxl19 and StradB in adipogenesis, siRNA was used to knockdown these genes in primary SVF cultures (Supplemental Fig. S7E). As expected, knockdown of Pparg2, an essential regulator of adipogenesis, strongly inhibited adipogenic differentiation (Supplemental Fig. S7F). While StradB knockdown had no effect, reduced Fbxl19 expression dramatically impaired adipogenesis in wild-type SVFs (Fig. 6E; Supplemental Fig. S7F). Accordingly, adipogenic gene expression was strongly reduced in Fbxl19, but not StradB, knockdown cultures (Fig. 6F; Supplemental Fig. S7G). Moreover, knockdown of Fbxl19 in miR-26-TKO cultures restored adipogenesis to wild-type levels (Fig. 6E,F). Conversely, overexpression of FBXL19 robustly stimulated adipogenesis to an extent that was comparable to the effect of PPAR $\gamma 2$ overexpression (Fig. 6G,H) and strongly induced adipogenic gene expression (Fig. 6I).

Finally, we tested the ability of miR-26 to directly regulate Fbxl19 expression. The Fbxl19 3' UTR contains two closely spaced highly conserved 8 mer binding sites for miR-26 (Fig. 6J; Agarwal et al. 2015). Placement of these sites within the $3^{\prime}$ UTR of a luciferase reporter transcript 
A

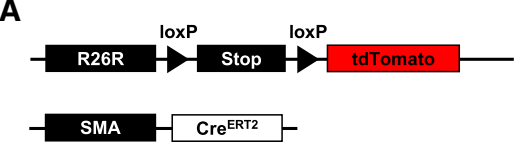

B

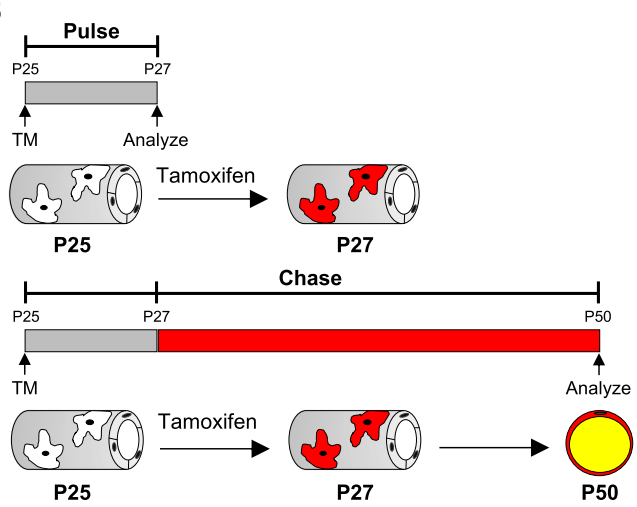

D

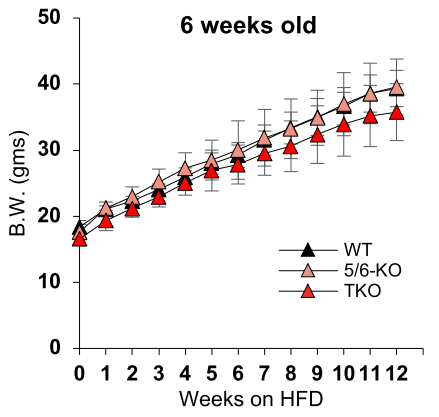

E

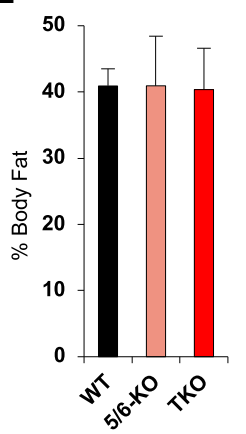

C

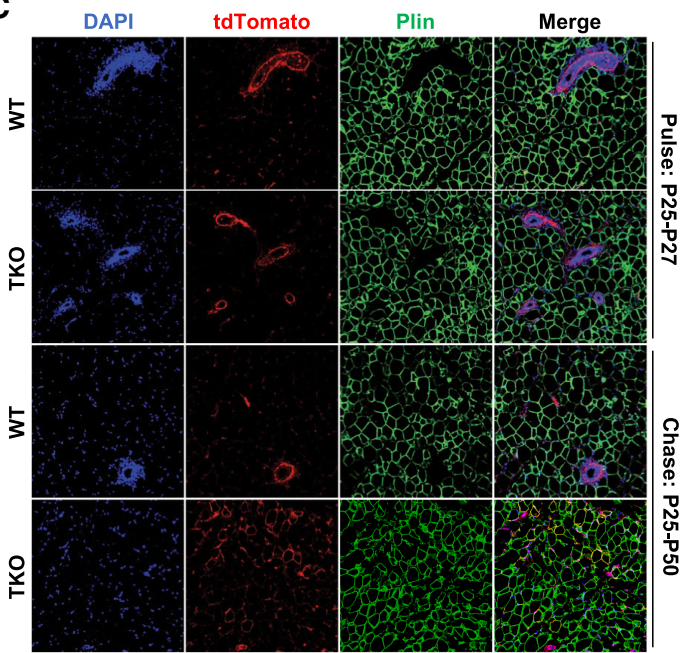

F

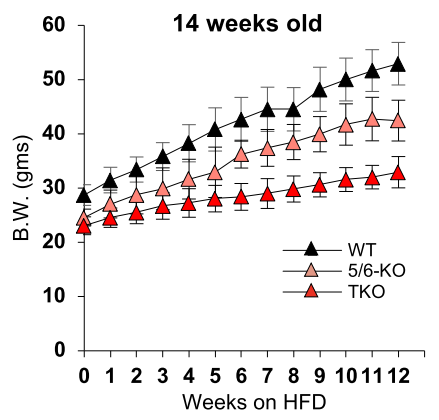

G

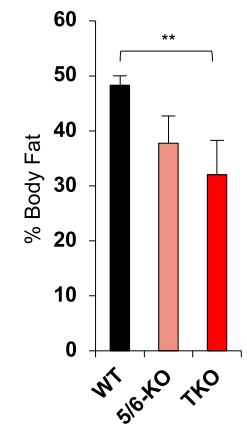

H

I
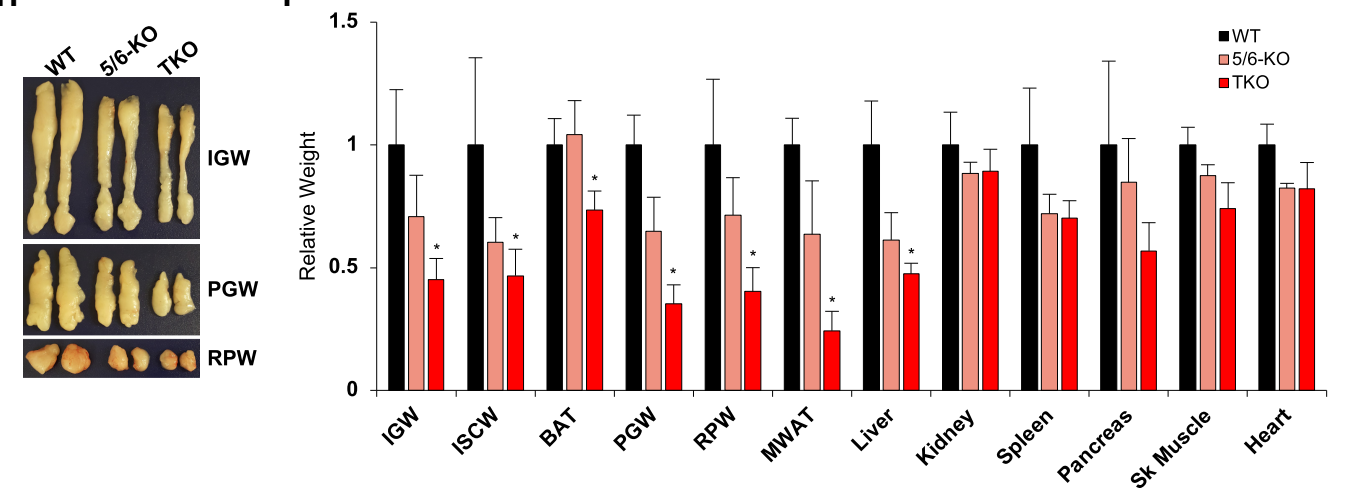

Figure 5. Loss of miR-26 results in precocious differentiation and depletion of APCs. (A) Schematic of transgenes used for lineage tracing of adult APCs in wild-type and miR-26-TKO mice. $(B)$ Experimental time course. Adult wild-type and miR-26-TKO mice were pulsed with tamoxifen (TM) at postnatal day 25 (P25) to label the APCs with tdTomato using SMA-Cre $e^{E R T 2 /+}$ and $R 26 R^{t d T /+}$. One-half of the animals from both genotypes were sacrificed on P27 to ensure efficient labeling. Reporter expression in the remaining mice was analyzed at P50 to assess adipocyte labeling. $(C)$ Representative stained sections of IGW fat depots from mice of the indicated genotypes, induced with tamoxifen at P25 and analyzed at P27 (Pulse, top half) or P50 (Chase, bottom half). R26R $R^{t d T /+}$ expression was detected by antibody staining for tdTomato (red) on FFPE sections. Nuclei are marked with DAPI (blue) and Perilipin (Plin) marks mature adipocytes (green). These data are representative of two independent experimental cohorts of animals. $(D)$ Body weight of mice of indicated genotypes fed HFD starting at $6 \mathrm{wk}$ of age ( $n=10-12$ mice per genotype) recorded weekly. (E) Whole-body fat content of mice in $D$ measured by NMR after 12 wk on HFD. $(F)$ Body weight of mice of indicated genotypes fed HFD starting at 14 wk of age $(n=10-12$ per genotype) recorded weekly. ( $G)$ Whole-body fat content of mice in $F$ measured by NMR after 12 wk on HFD. (H) Representative whole-mount images of subcutaneous (IGW) and visceral (PGW and RPW) fat depots from mice in $F$ after $12 \mathrm{wk}$ on HFD. (I) Relative weights of isolated fat depots and major organs of mice in $F$ after 12 wk on HFD. Data represented as mean \pm SD. $\left({ }^{*}\right) P<0.05 ;\left(^{* *}\right) P<0.01$, calculated using two-tailed $t$-test. 
A

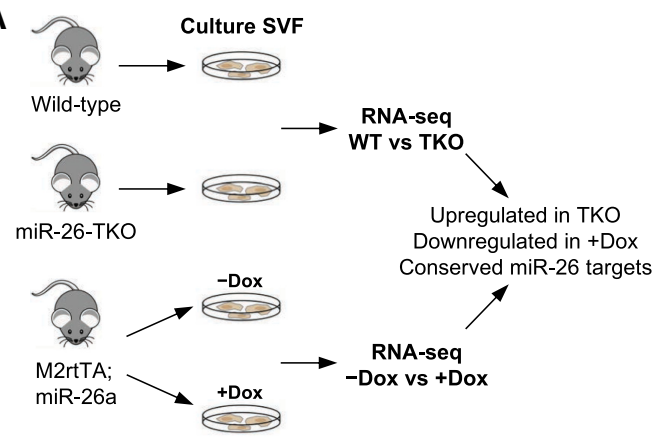

E

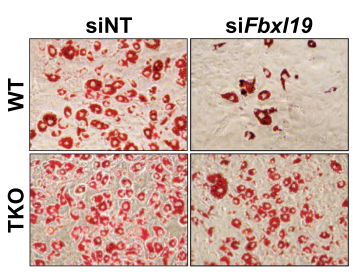

G

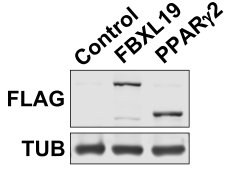

H

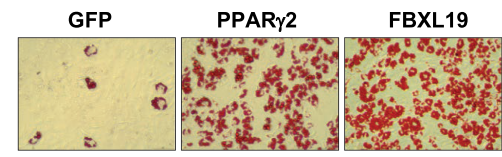

J

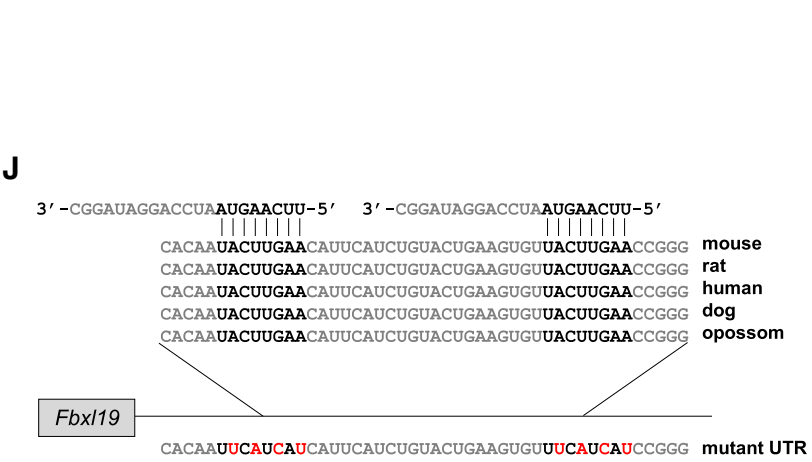

B

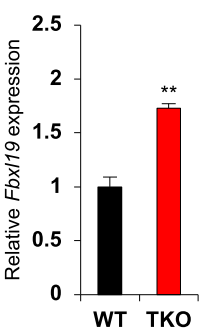

C

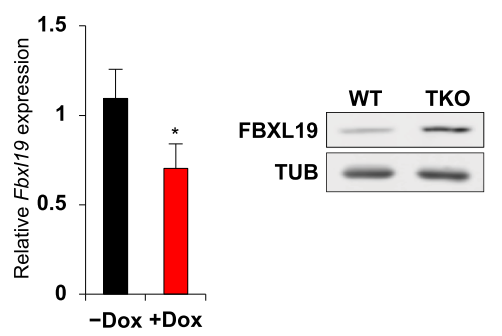

$\mathbf{F}$

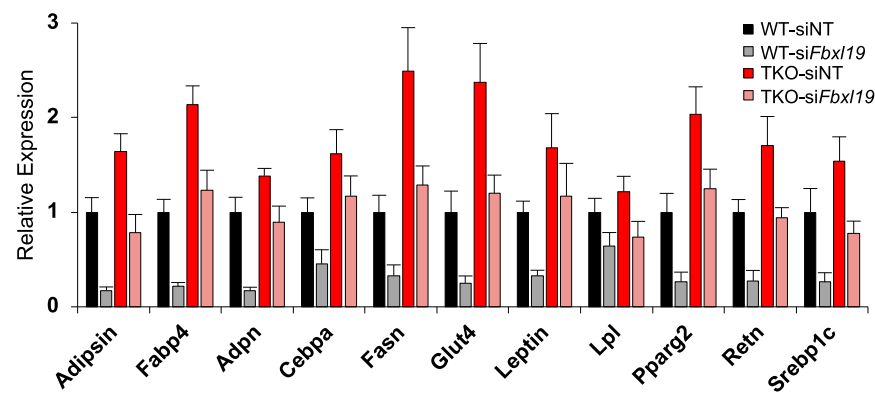

I
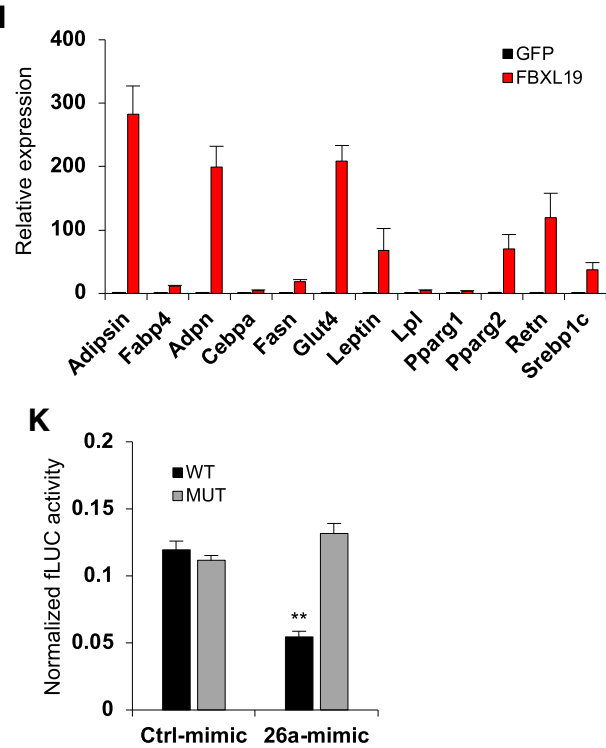

Figure 6. Fbxl19 is a conserved miR-26 target that promotes adipogenesis. (A) Experimental design to identify candidate miR-26 targets that regulate adipogenesis. RNA-seq was used to identify (1) genes up-regulated in miR-26-TKO vs. wild-type SVF cultures and (2) genes down-regulated in dox-treated versus untreated SVF cultures from miR-26a transgenic mice $(M 2 r t T A ; m i R-26 a)$. Genes were further filtered for Targetscan7.2-predicted miR-26 targets (http://www.targetscan.org). (B,C) qRT-PCR analysis of Fbxl19 expression in wild-type and miR-26-TKO SVFs $(B)$ and miR-26a transgenic SVFs with or without dox treatment $(C) . n=3$ biological replicates. $(D)$ Western blot of FBXL19 protein levels in wild-type and miR-26-TKO SVFs. Data are representative of three independent experiments. $\alpha$-tubulin (TUB) represents a loading control. (E) Representative images of Oil Red O-stained in vitro differentiated wild-type or miR-26-TKO SVF cultures following siRNA knockdown of Fbx119. siNT, nontargeting control siRNA. $(F)$ qRT-PCR analysis of adipogenic gene expression in SVF cultures in E. (G) Western blot of Flag-tagged mouse FBXL19 or PPAR $\gamma 2$ in transfected wild-type SVF cultures. $(H)$ Representative images of Oil Red O-stained SVF cultures after overexpression of the indicated proteins. (I) qRT-PCR analysis of adipogenic gene expression in SVF cultures with GFP or FBXL19 overexpression. (J) Schematic representation of conserved miR-26 binding sites in the 3' UTR of Fbx119. Mutations introduced to disrupt miR-26-binding are shown below the alignment and highlighted in red. $(K)$ Relative firefly luciferase activity of reporter constructs containing wild-type or mutant miR-26-binding sites from the Fbxl19 3' UTR following cotransfection with control or miR-26a mimics. Data represent the average of three independent experiments, each performed with technical triplicates. Data represented as mean $\pm \mathrm{SD}\left({ }^{*}\right) P<0.05 ;\left(^{* *}\right) P<0.01$, calculated using two-tailed $t$-test. 
was sufficient to confer miR-26-mediated repression, which was abolished by mutations that disrupted interaction with the miR-26 seed sequence (Fig. 6K). Together, these data validate Fbx119 as a direct miR-26 target and support its role as a regulator of adipogenesis that functions downstream from the miR-26 family within the APC lineage.

\section{Discussion}

Obesity, or excess body fat, is a global health problem that represents a major risk factor for several chronic diseases, including type 2 diabetes, nonalcoholic fatty liver disease, cardiovascular disease, stroke, and cancer. The molecular mechanisms that regulate adipose tissue homeostasis are key to understanding the pathogenesis of obesity and metabolic dysfunction. Nevertheless, the genes and pathways that influence adipocyte size and number in vivo remain incompletely understood. Here we describe a new pathway that plays a critical role in the control of adipogenesis in vitro and in vivo. Through the characterization of mice lacking the highly conserved miR-26 miRNA family, we unexpectedly discovered that loss of these miRNAs results in the dramatic expansion of adipose tissue early in adult life. Several lines of evidence, including in vitro differentiation assays, lineage-specific miRNA overexpression experiments, and fate mapping of adult APCs in knockout animals, established that this phenotype is due to a cell-autonomous function of miR-26 as a suppressor of adipogenic differentiation. Furthermore, Fbxl19, which encodes a component of Skp-Cullin-F-box-containing (SCF) E3 ubiquitin ligase complexes and epigenetic regulator, was validated as a novel miR-26 target that functions downstream from this miRNA family to drive adipogenesis. These studies therefore establish a previously uncharacterized miR-26-Fbxl19 axis as a major regulator of APC mobilization and adipose tissue expansion in mammals (Fig. 7).

Given their ability to proliferate and produce new adipocytes, a population of perivascular APCs are now appreciated to function as crucial regulators of WAT maintenance and expansion (Berry et al. 2016; Hepler et al. 2017). Genetic lineage tracing methodologies have been instrumental in establishing the importance of this cell population for adult adipose tissue homeostasis. Fate mapping studies have provided direct evidence that

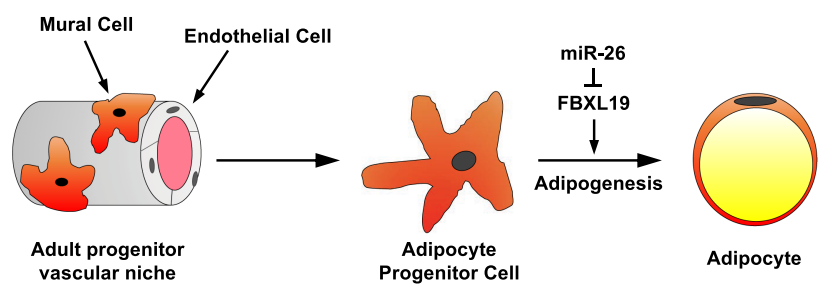

Figure 7. miR-26 suppresses adipocyte progenitor cell differentiation. miR-26 functions within the APC lineage to inhibit mobilization and subsequent adipocyte production by downregulating FBXL19, a novel driver of adipogenesis. a subpopulation of mural cells characterized by distinct marker gene expression $\left(\mathrm{SMA}^{+}\right.$; $\mathrm{PDGFR} \beta^{+}$; $\mathrm{PDGFR}{ }^{+}$;

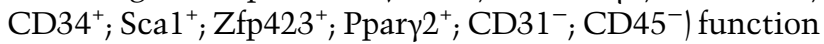
as adipocyte precursors that contribute to the maintenance and high-fat diet-induced expansion of adipose depots in adult mice (Gupta et al. 2012; Jiang et al. 2014; Vishvanath et al. 2016). Our studies of the miR-26 family have revealed a new pathway that robustly regulates the behavior of these cells in vivo. Loss of miR-26 triggers precocious APC differentiation, resulting in adipocyte hyperplasia and WAT expansion, in a manner that resembles the physiologic response to caloric excess. Over time, excessive APC differentiation leads to a depletion of this progenitor compartment, such that older miR-26-TKO mice exhibit impaired weight gain and adipogenesis when fed a HFD. On the other hand, enforced miR-26 expression strongly suppresses activation of APCs, robustly suppressing WAT expansion. These findings have therefore uncovered a previously unanticipated miRNA-mediated checkpoint that plays a critical role in controlling APC mobilization.

The discovery of a role for miR-26 as a regulator of adult adipogenesis expands our understanding of the functions of this miRNA family in mammalian metabolic homeostasis. Previously, miR-26 was found to be down-regulated in the livers of obese humans and mice (Fu et al. 2015; Kim et al. 2019). Hepatic overexpression of miR-26a was demonstrated to improve, whereas miR-26 inhibition was shown to decrease insulin sensitivity (Fu et al. 2015). Our studies have revealed the adipose tissue, and the APC population specifically, as another major site of miR-26 action in the regulation of systemic metabolism. Enforced miR-26 expression in the APC lineage was sufficient to block HFD-associated weight gain, adipose tissue expansion, hyperglycemia, and hyperlipidemia. Interestingly, it has recently been suggested that exosome-mediated miRNA transfer from adipose tissue-derived immune cell populations to other tissues, such as liver, muscle, and pancreas, modulates insulin sensitivity (Ying et al. 2017; Guay et al. 2019). In light of these findings, and the potent effects of miR-26 expression on APC differentiation, future studies are warranted to examine whether transfer of miR-26 from immune cells to APCs provides a mechanism to regulate the APC population and, consequently, fat production.

In addition to revealing a critical role for miR-26 in controlling adult adipogenesis, these studies have also uncovered a new role for FBXL19 as a major regulator of this process. FBXL19 is a component of SCF E3 ubiquitin ligase complexes that mediate targeted ubiquitylation of proteins destined for proteasomal degradation (Jin et al. 2004). Of the $>70$ F-box proteins that have been identified in humans, the most well-studied facilitate degradation of cell cycle regulators (Nakayama and Nakayama 2006). Previous work has identified a limited number of ubiquitylated substrates of FBXL19, including members of the Ras and Rho family of small GTPases and a receptor for IL-33, implicating the protein in diverse cellular functions including proliferation, migration, apoptosis, and immune responses (Zhao et al. 2012, 2013; Dong et al. 
2014). More recent work has highlighted a nuclear role for FBXL19 as a CpG island-binding protein via its N-terminal CxxC-Zn finger domain (Lee et al. 2017; Dimitrova et al. 2018). Upon binding CpG islands upstream of genes involved in lineage specification, FBXL19 activates gene expression by promoting RNF20-mediated histone H2B mono-ubiquitylation and/or by directly recruiting the mediator complex, thereby promoting embryonic stem cell differentiation. In principle, both the targeted proteasomal degradation of FBXL19 ubiquitylation substrates as well as the activation of lineage-specific gene expression could contribute to the adipogenic properties of this protein. Elucidation of the downstream pathways controlled by FBXL19 in adipocyte progenitors therefore represents an important priority for future work and is likely to reveal new mechanisms that impact adipose tissue homeostasis.

In sum, the data reported here highlight the potentially beneficial effects of increasing miR-26 activity, or inhibiting its downstream targets, in the setting of obesity. This concept is further supported by the observation that sustained global overexpression of miR-26 does not result in any overt toxicities in mice (Zeitels et al. 2014). Further investigation of the miR-26-Fblx19 pathway as well as the identification of additional miR-26 targets that mediate the beneficial metabolic activities of these miRNAs promises to reveal new insights into the biology of obesity and potentially new therapeutic strategies.

\section{Materials and methods}

\section{Mouse strains}

miR-26-TKO mice were generated and maintained on a pure C57Bl/ 6 background. Mice were housed in a 12-h light-dark cycle with normal chow (Harlan Teklad, TD.2916) provided ad libitum. Wild-type C57Bl/6 mice (Jackson Laboratory, 000664) were obtained from the mouse-breeding core at the University of Texas Southwestern Medical Center and maintained in the same colony. SMA-Cre $e^{E R T 2 /+}$ mice were generously provided by Dr. Pierre Chambon (IGCMB, Strasbourg, France). Activation of Cre recombinase in these mice was achieved by tamoxifen administration $(0.1 \mathrm{mg} / \mathrm{g}$ body weight) by oral gavage. Generation of LSL.eGFP.miR-26a transgenic mice was described previously (Zeitels et al. 2014). To induce miR-26a expression, dox $(2 \mathrm{mg} / \mathrm{mL}$ in $1 \%$ sucrose) was provided in drinking water starting at $6 \mathrm{wk}$ of age. Unless otherwise specified, for HFD studies, male mice were fed a high-fat high-sucrose diet (Research Diets, D12331) for a total duration of $12 \mathrm{wk}$, starting at 6-8 wk of age. All animal studies were approved by the University of Texas Southwestern Medical Center Animal Care and Use Committee in accordance with NIH guidelines (Animal protocols 2017-102001 and 2015-101187).

\section{T7 endonuclease assay}

Plasmid pX330 expressing Cas9 and sgRNA (Cong et al. 2013) was linearized with $B b s 1$. A pair of oligonucleotides (sequences provided in Supplemental Table S1) corresponding to each of the individual miR-26 family members was annealed and ligated to the linearized vector. E14 mouse embryonic stem (mES) cells were maintained in Dulbecco's knockout media supplemented with $15 \%$ fetal bovine serum (Sigma), 2 mM GlutaMAX (Life Technol- ogies), nonessential amino acids $(1 \times)$, Sodium pyruvate $(1 \mathrm{mM})$, LIF (Millipore), $\beta$-ME (Sigma), $100 \mathrm{U} / \mathrm{mL}$ penicillin, and $100 \mu \mathrm{g} /$ $\mathrm{mL}$ streptomycin. Cells were transfected with plasmid DNA using X-Fect mESC Transfection Reagent (Clontech, PT5004-2). After 48 h, genomic DNA was extracted using DNeasy Blood and Tissue kit (Qiagen) following manufacturer's protocol. Genomic DNA surrounding the CRISPR target site for each of the miR-26 genes was PCR amplified (primer sequences in Supplemental Table S1) and the products were purified using QiaQuick spin columns (Qiagen). A total of $200 \mathrm{ng}$ of the purified PCR product was subjected to denaturation followed by gradual reannealing to enable heteroduplex formation (for $10 \mathrm{~min}$ at $95^{\circ} \mathrm{C}, 95^{\circ} \mathrm{C}$ to $85^{\circ} \mathrm{C}$ ramping at $2^{\circ} \mathrm{C} / \mathrm{sec}, 85^{\circ} \mathrm{C}$ to $25^{\circ} \mathrm{C}$ ramping at $0.25^{\circ} \mathrm{C} / \mathrm{sec}$, and hold for $1 \mathrm{~min}$ at $25^{\circ} \mathrm{C}$ ). Reannealed PCR products were digested with T7 endonuclease (New England Biolabs), and the digested products were analyzed on a $1 \%$ agarose gel.

\section{CRISPR/Cas9-mediated genome editing of miR-26 loci}

For editing of miR-26 genomic loci, Cas 9 mRNA and sgRNAs were coinjected into the pronucleus of fertilized C57BL/6 onecell eggs following in vitro transcription (Wang et al. 2013a). Briefly, T7-Cas9 or T7-sgRNA PCR products (primer sequences in Supplemental Table S1) were gel purified and used as the template for in vitro transcription (IVT) using the mMESSAGE mMACHINE T7 ULTRA kit (Life Technologies) or the MEGAshortscript T7 kit (Life Technologies), respectively. Both Cas9 mRNA and sgRNAs were purified using the MEGAclear kit (Life Technologies) and eluted in RNase-free water. Founders with disrupted miRNA seed sequences were identified by TA cloning and Sanger sequencing. Founders with deletions of the seed sequence were crossed with C57BL/6 mice for six generations followed by intercrossing to generate the global miR-26 triple knockout. Since the probability of obtaining a TKO and wildtype in the same cross is very low (1/64 in a triple heterozygote cross), knockouts were compared to age- and sex-matched wildtype C57BL/6 mice bred under the same conditions. Additionally, as a littermate control, 5/6-KO mice (deleted for five of the six miR-26 alleles, bearing only one functional allele of miR-26a-2) were also included in most analyses.

\section{SVF culture and differentiation}

All in vitro differentiation assays were performed as previously described (Tang et al. 2008) using primary stromal vascular fraction (SVF) cultures derived from 6- to 8-wk-old adult mice. Briefly, subcutaneous and visceral white fat depots were pooled, minced, and digested by slow shaking in adipocyte isolation buffer $(100 \mathrm{mM}$ HEPES at $\mathrm{pH} 7.4,120 \mathrm{mM} \mathrm{NaCl}, 50 \mathrm{mM} \mathrm{KCl}, 5 \mathrm{mM}$ glucose, $1 \mathrm{mM} \mathrm{CaCl}_{2}, 1.5 \% \mathrm{BSA}, 1 \mathrm{mg} / \mathrm{mL}$ collagenase type I) for $2 \mathrm{~h}$ at $37^{\circ} \mathrm{C}$. The suspension was then centrifuged at $800 \mathrm{rpm}$ for $10 \mathrm{~min}$ to yield the floating adipocyte layer and the crude stromal vascular (SV) pellet. The pellet was first suspended in erythrocyte lysis buffer, filtered through a $100-\mu \mathrm{m}$ mesh, and spun at $1300 \mathrm{rpm}$ for $5 \mathrm{~min}$. The resulting pellet was suspended in $1 \times$ PBS, passed through a $40-\mu \mathrm{m}$ mesh, and spun at $1300 \mathrm{rpm}$ for $5 \mathrm{~min}$ to obtain the SVF. Cells from the SVF were cultured in DMEM supplemented with $10 \%$ FBS. Dox was added to induce miR-26a overexpression in SVF cultures derived from transgenic mice (M2rtTA; eGFP.miR-26a) at a concentration of $1 \mu \mathrm{g} / \mathrm{mL}$. LNA inhibitors for miR-26a and miR-26b (Exiqon, Inc.) and siRNA SMARTpools (Dharmacon) targeting mouse Fbx119, StradB, and Ppary2 were reverse-transfected into primary SVFs using RNAiMax (Thermo Fisher Scientific). Knockdown efficiency was monitored $48 \mathrm{~h}$ after transfection by qRT-PCR. Overexpression of FBXL19 and 
PPAR $\gamma 2$ in primary SVF cultures was achieved by nucleofection using the SE cell line 4D-Nucleofector X-kit (Lonza). Flag-tagged ORF clones for FBXL19 (Origene, MR209945) and PPAR $\gamma 2$ (Origene, MR208132) were transfected into wild-type SVFs $\left(\sim 3 \times 10^{5}\right.$ cells) using the CM137 program. Differentiation was induced $2 \mathrm{~d}$ after the cells had reached confluency using an adipogenic cocktail containing $5 \mu \mathrm{M}$ dexamethasone, $0.5 \mu \mathrm{g} / \mathrm{mL}$ insulin, and $0.5 \mathrm{mM}$ isobutylmethylxanthine in culture medium. After $72 \mathrm{~h}$, medium was replaced with DMEM containing $0.5 \mu \mathrm{g} / \mathrm{mL}$ insulin. Oil Red O staining was performed as previously described (Tang et al. 2008). Briefly, differentiated adipocytes were fixed in $4 \%$ paraformaldehyde for $30 \mathrm{~min}$, washed with deionized water, and incubated in 60\% isopropanol for $10 \mathrm{~min}$. Adipocytes were then stained in Oil Red O solution for 30 min, rinsed with tap water, and imaged using a Nikon Eclipse TS100 inverted microscope.

\section{Metabolic phenotyping assays}

Blood glucose was measured in tail blood using a Bayer Contour blood glucose monitoring system. For serum measurements, blood was collected by cardiac puncture, incubated at room temp for $30 \mathrm{~min}$, and centrifuged at $8000 \mathrm{rpm}$ for $10 \mathrm{~min}$ to obtain the serum. Serum triglyceride, cholesterol, and NEFA were measured in adult mice in the UT Southwestern Metabolic Phenotyping Core. GTT was performed as previously described (Zeve et al. 2012). Total body fat mass of mice was measured by NMR spectroscopy using a Minispec mq spectrometer (Bruker).

Metabolic cage studies

Wild-type, 5/6-KO, and miR-26-TKO mice on normal chow were monitored in metabolic chambers. Mice were housed individually and acclimatized to the metabolic chambers for $5 \mathrm{~d}$ before data collection was initiated. For the subsequent $5 \mathrm{~d}$, food intake, $\mathrm{VO}_{2}$, $\mathrm{VCO}_{2}$, and physical activity were monitored over a 12-h light/ dark cycle with food provided ad libitum.

\section{RNA extraction, quantitative RT-PCR, and RNA-seq}

Total RNA was isolated using the miRNeasy Mini Kit (Qiagen) according to the manufacturer's instructions. Pre-designed TaqMan primers and probes (Life Technologies) were used to measure the levels of mature miR-26a, miR-26b, miR-19b, and U6 snRNA according to the manufacturer's protocol. All other mRNAs were reverse transcribed using PrimeScript reverse transcription master mix (Takara) and transcript abundance was assayed using Power SYBR Green master mix (Life Technologies). All qRT-PCR values were normalized using 18S rRNA expression as a loading control. Primer sequences are provided in Supplemental Table S1.

RNA-seq experiments were performed on triplicate samples from SVFs from (1) wild-type C57BL/6 and miR-26-TKO mice, and (2) M2rtTA; eGFP.miR-26a mice with or without $1 \mu \mathrm{g} / \mathrm{mL}$ dox treatment for $4 \mathrm{~d}$. Library prep and RNA-seq were performed by the UTSW McDermott Center Next-Generation Sequencing Core. Sequencing libraries were prepared with the TruSeq Stranded mRNA Library Prep Kit (Illumina) and sequenced using the 75bp single-read protocol on a NextSeq 500 (Illumina). Reads were mapped to the mouse reference genome (GRCm38) using HISAT2 (version 2.1.0) (Pertea et al. 2016). Only reads uniquely mapped to the genome were kept for future analysis. Aligned reads were counted per gene ID using feature counts (v.1.6.0) (Liao et al. 2014) based on the annotation of GENCODE M16
(Mudge and Harrow 2015). Differential expression analysis was performed using edgeR (3.24.0) (McCarthy et al. 2012).

\section{Histology, immunohistochemistry, and Western blotting}

Hematoxylin and eosin (H\&E) staining and immunocytochemistry were performed on paraffin sections as described previously (Tang et al. 2008). Isolated tissues were fixed in $10 \%$ formalin, embedded in paraffin, and sectioned with a HM 325 microtome. tdTomato reporter expression in paraffin sections was visualized by immunostaining with a mouse monoclonal antibody against DsRed (Takara, 632392) used at a 1:200 dilution. Adipocytes were identified by immunostaining with anti-Perilipin-1 (Abcam, ab61682) used at 1:1000. For Western blotting, whole-cell extracts of cultured SVFs were immunoblotted with anti-FBXL19 (1:1000; Abcam, ab172961), anti-a-Tubulin (1:2000; Sigma, T6199), and anti-Flag epitope (1:1000; Cell Signaling, 2368).

\section{Flow cytometry}

For FACS analysis of tdTomato+ cells, freshly isolated SVFs from 6-wk-old control (SMA-Cre ${ }^{E R T 2 /+} ; R 26 R^{t d T /+}$ ) or knockout (SMA$C r e^{E R T 2 /+} ; R 26 R^{\text {tdT+/- }} ; \mathrm{miR}$-26-TKO) mice were stained for stem cell antigen Sca-1 (1:200 antimouse Ly-6A/E antibody, BD biosciences, 560653) for $30 \mathrm{~min}$ on ice followed by two washes with staining buffer (PBS with $3 \%$ FBS and 2 mM EDTA, pH 8.0). Cells were analyzed with a BD FACS Aria at the UT Southwestern Flow Cytometry Core. Data analysis was performed using BD FACS Diva software.

\section{Luciferase reporter assays}

The wild-type reporter construct was created by cloning a 372-bp fragment of the mouse Fbxl19 3' UTR encompassing the two conserved miR-26 binding sites into the XbaI site of pGL3-control (Promega). Mutagenesis was performed by amplifying the plasmid using overlapping oligonucleotides that contained mutations in both miR-26-binding sites (oligonucleotide sequences in Supplemental Table S1). HCT116 cells $\left(1 \times 10^{5}\right.$ per well) were plated in a 24 -well plate $16 \mathrm{~h}$ prior to transfecting $100 \mathrm{ng}$ of the indicated reporter construct, along with 5 ng of phRL-SV40 (Promega) and $25 \mathrm{nM}$ of control or miR-26a mimic (Dharmacon) using Lipofectamine 2000 (Thermo Fisher Scientific). Firefly and renilla luciferase activity were assayed $48 \mathrm{~h}$ after transfection using the Dual Luciferase Reporter Assay System 4 (Promega) according to the manufacturer's protocol.

\section{Data access}

RNA-seq data have been deposited in GEO under accession code GSE134736.

\section{Acknowledgments}

We thank Pierre Chambon for mouse strains, Feng Zhang for plasmids, Jeanetta Marshburn-Wynn and Frank Gillett for assistance with mouse husbandry, Mylinh Nguyen and the University of Texas Southwestern Transgenic Core for mouse generation, Vanessa Schmid and the McDermott Center Next-Generation Sequencing Core for high-throughput sequencing, Ruth Gordillo and Syann Lee at the University of Texas Southwestern Metabolic Phenotyping Core for phenotypic analyses, Angie Mobley and the University of Texas Southwestern Flow Cytometry Core for cell sorting, and Kathryn O'Donnell and members of the Mendell 
laboratory for helpful comments on the manuscript. This work was supported by grants from Cancer Prevention and Research Institute of Texas (RP160249 to J.T.M.; RP150596 to the University of Texas Southwestern Bioinformatics Core Facility), National Institutes of Health (R35CA197311, P30CA142543, and P50CA196516 to J.T.M., and K01DK109027 to D.C.B.), and the Welch Foundation (I-1961-20180324 to J.T.M.). J.T.M. is an Investigator of the Howard Hughes Medical Institute.

Author contributions: A.A. performed most experiments. Y.J. and B.T.J. assisted with histologic analyses. R.E.H. supervised mouse genome editing. H.Z. performed bioinformatic analyses. A.A., D.C.B., J.M.G., and J.T.M. designed and interpreted experiments. A.A. and J.T.M. wrote the manuscript.

\section{References}

Agarwal V, Bell GW, Nam JW, Bartel DP. 2015. Predicting effective microRNA target sites in mammalian mRNAs. Elife 4: e05005. doi:10.7554/eLife.05005

Bartel DP. 2009. MicroRNAs: target recognition and regulatory functions. Cell 136: 215-233. doi:10.1016/j.cell.2009.01.002

Bartel DP. 2018. Metazoan MicroRNAs. Cell 173: 20-51. doi:10 $.1016 /$ j.cell.2018.03.006

Berry R, Rodeheffer MS. 2013. Characterization of the adipocyte cellular lineage in vivo. Nat Cell Biol 15: 302-308. doi:10 $.1038 / \mathrm{ncb} 2696$

Berry DC, Stenesen D, Zeve D, Graff JM. 2013. The developmental origins of adipose tissue. Development 140: 3939-3949. doi:10.1242/dev.080549

Berry DC, Jiang Y, Graff JM. 2016. Emerging roles of adipose progenitor cells in tissue development, homeostasis, expansion and thermogenesis. Trends Endocrinol Metab 27: 574-585. doi:10.1016/j.tem.2016.05.001

Blüher M. 2014. Adipokines-removing road blocks to obesity and diabetes therapy. Mol Metab 3: 230-240. doi:10.1016/j .molmet.2014.01.005

Boudeau J, Baas AF, Deak M, Morrice NA, Kieloch A, Schutkowski M, Prescott AR, Clevers HC, Alessi DR. 2003. MO25 $\alpha / \beta$ interact with STRAD $\alpha / \beta$ enhancing their ability to bind, activate and localize LKB1 in the cytoplasm. EMBO I 22: 51025114. doi:10.1093/emboj/cdg490

Cong L, Ran FA, Cox D, Lin S, Barretto R, Habib N, Hsu PD, Wu $\mathrm{X}$, Jiang W, Marraffini LA, et al. 2013. Multiplex genome engineering using CRISPR/Cas systems. Science 339: 819-823. doi:10.1126/science. 1231143

Deng Y, Scherer PE. 2010. Adipokines as novel biomarkers and regulators of the metabolic syndrome. Ann N Y Acad Sci 1212: E1-E19. doi:10.1111/j.1749-6632.2010.05875.x

Dey BK, Gagan J, Yan Z, Dutta A. 2012. miR-26a is required for skeletal muscle differentiation and regeneration in mice. Genes Dev 26: 2180-2191. doi:10.1101/gad.198085.112

Dill H, Linder B, Fehr A, Fischer U. 2012. Intronic miR-26b controls neuronal differentiation by repressing its host transcript, ctdsp2. Genes Dev 26: 25-30. doi:10.1101/gad.177774.111

Dimitrova E, Kondo T, Feldmann A, Nakayama M, Koseki Y, Konietzny R, Kessler BM, Koseki H, Klose RJ. 2018. FBXL19 recruits CDK-Mediator to CpG islands of developmental genes priming them for activation during lineage commitment. Elife 7: e37084. doi:10.7554/eLife.37084

Dong S, Zhao J, Wei J, Bowser RK, Khoo A, Liu Z, Luketich JD, Pennathur A, Ma H, Zhao Y. 2014. F-box protein complex FBXL19 regulates TGF $\beta 1$-induced E-cadherin down-regulation by mediating Rac3 ubiquitination and degradation. Mol Cancer 13: 76. doi:10.1186/1476-4598-13-76
Dooley J, Garcia-Perez JE, Sreenivasan J, Schlenner SM, Vangoitsenhoven R, Papadopoulou AS, Tian L, Schonefeldt S, Serneels L, Deroose C, et al. 2016. The microRNA-29 family dictates the balance between homeostatic and pathological glucose handling in diabetes and obesity. Diabetes 65: 5361. doi:10.2337/db15-0770

Fu X, Dong B, Tian Y, Lefebvre P, Meng Z, Wang X, Pattou F, Han W, Wang X, Lou F, et al. 2015. MicroRNA-26a regulates insulin sensitivity and metabolism of glucose and lipids. J Clin Invest 125: 2497-2509. doi:10.1172/JCI75438

Gebert LFR, MacRae IJ. 2019. Regulation of microRNA function in animals. Nat Rev Mol Cell Biol 20: 21-37. doi:10.1038/ s41580-018-0045-7

Guay C, Kruit JK, Rome S, Menoud V, Mulder NL, Jurdzinski A, Mancarella F, Sebastiani G, Donda A, Gonzalez BJ, et al. 2019. Lymphocyte-derived exosomal MicroRNAs promote pancreatic $\beta$ cell death and may contribute to Type 1 diabetes development. Cell Metab 29: 348-361.e6. doi:10.1016/j.cmet.2018 .09 .011

Gupta RK, Mepani RJ, Kleiner S, Lo JC, Khandekar MJ, Cohen P, Frontini A, Bhowmick DC, Ye L, Cinti S, et al. 2012. Zfp423 expression identifies committed preadipocytes and localizes to adipose endothelial and perivascular cells. Cell Metab 15: 230-239. doi:10.1016/j.cmet.2012.01.010

Ha M, Kim VN. 2014. Regulation of microRNA biogenesis. Nat Rev Mol Cell Biol 15: 509-524. doi:10.1038/nrm3838

Hepler C, Vishvanath L, Gupta RK. 2017. Sorting out adipocyte precursors and their role in physiology and disease. Genes Dev 31: 127-140. doi:10.1101/gad.293704.116

Icli B, Wara AK, Moslehi J, Sun X, Plovie E, Cahill M, Marchini JF, Schissler A, Padera RF, Shi J, et al. 2013. MicroRNA-26a regulates pathological and physiological angiogenesis by targeting BMP/SMAD1 signaling. Circ Res 113: 1231-1241. doi:10 .1161 /CIRCRESAHA.113.301780

Jeffery E, Church CD, Holtrup B, Colman L, Rodeheffer MS. 2015. Rapid depot-specific activation of adipocyte precursor cells at the onset of obesity. Nat Cell Biol 17: 376-385. doi:10.1038/ ncb3122

Ji J, Shi J, Budhu A, Yu Z, Forgues M, Roessler S, Ambs S, Chen Y, Meltzer PS, Croce CM, et al. 2009. MicroRNA expression, survival, and response to interferon in liver cancer. $N$ Engl $J$ Med 361: 1437-1447. doi:10.1056/NEJMoa0901282

Jiang Y, Berry DC, Tang W, Graff JM. 2014. Independent stem cell lineages regulate adipose organogenesis and adipose homeostasis. Cell Rep 9: 1007-1022. doi:10.1016/j.celrep.2014.09 .049

Jin J, Cardozo T, Lovering RC, Elledge SJ, Pagano M, Harper JW. 2004. Systematic analysis and nomenclature of mammalian F-box proteins. Genes Dev 18: 2573-2580. doi:10.1101/gad .1255304

Joe AW, Yi L, Even Y, Vogl AW, Rossi FM. 2009. Depot-specific differences in adipogenic progenitor abundance and proliferative response to high-fat diet. Stem Cells 27: 2563-2570. doi:10.1002/stem.190

Jonas S, Izaurralde E. 2015. Towards a molecular understanding of microRNA-mediated gene silencing. Nat Rev Genet 16: 421433. doi:10.1038/nrg3965

Kim NH, Ahn J, Choi YM, Son HJ, Choi WH, Cho HJ, Yu JH, Seo JA, Jang YJ, Jung CH, et al. 2019. Differential circulating and visceral fat microRNA expression of non-obese and obese subjects. ClinNutr doi:10.1016/j.clnu.2019.03.033

Kota J, Chivukula RR, O'Donnell KA, Wentzel EA, Montgomery CL, Hwang HW, Chang TC, Vivekanandan P, Torbenson M, Clark KR, et al. 2009. Therapeutic microRNA delivery 
suppresses tumorigenesis in a murine liver cancer model. Cell 137: 1005-1017. doi:10.1016/j.cell.2009.04.021

Krol J, Loedige I, Filipowicz W. 2010. The widespread regulation of microRNA biogenesis, function and decay. Nat Rev Genet 11: 597-610. doi:10.1038/nrg2843

Lee BK, Lee J, Shen W, Rhee C, Chung H, Kim J. 2017. Fbxl19 recruitment to $\mathrm{CpG}$ islands is required for Rnf20-mediated H2B mono-ubiquitination. Nucleic Acids Res 45: 7151-7166. doi:10.1093/nar/gkx310

Lefterova MI, Zhang Y, Steger DJ, Schupp M, Schug J, Cristancho A, Feng D, Zhuo D, Stoeckert CJ, Liu XS, et al. 2008. PPAR $\gamma$ and C/EBP factors orchestrate adipocyte biology via adjacent binding on a genome-wide scale. Genes Dev 22: 2941-2952. doi:10.1101/gad.1709008

Liao Y, Smyth GK, Shi W. 2014. featureCounts: an efficient general purpose program for assigning sequence reads to genomic features. Bioinformatics 30: 923-930. doi:10.1093/bioinfor matics/btt656

Martin KA, Mani MV, Mani A. 2015. New targets to treat obesity and the metabolic syndrome. Eur I Pharmacol 763: 64-74. doi:10.1016/j.ejphar.2015.03.093

McCarthy DJ, Chen Y, Smyth GK. 2012. Differential expression analysis of multifactor RNA-seq experiments with respect to biological variation. Nucleic Acids Res 40: 4288-4297. doi:10.1093/nar/gks042

Mendell JT, Olson EN. 2012. MicroRNAs in stress signaling and human disease. Cell 148: 1172-1187. doi:10.1016/j.cell.2012 .02 .005

Mudge JM, Harrow J. 2015. Creating reference gene annotation for the mouse C57BL6/J genome assembly. Mamm Genome 26: 366-378. doi:10.1007/s00335-015-9583-x

Najafi-Shoushtari SH, Kristo F, Li Y, Shioda T, Cohen DE, Gerszten RE, Naar AM. 2010. MicroRNA-33 and the SREBP host genes cooperate to control cholesterol homeostasis. Science 328: 1566-1569. doi:10.1126/science.1189123

Nakayama KI, Nakayama K. 2006. Ubiquitin ligases: cell-cycle control and cancer. Nat Rev Cancer 6: 369-381. doi:10 $.1038 / \mathrm{nrc} 1881$

Nielsen R, Pedersen TA, Hagenbeek D, Moulos P, Siersbaek R, Megens E, Denissov S, Borgesen M, Francoijs KJ, Mandrup S, et al. 2008. Genome-wide profiling of PPAR $\gamma:$ RXR and RNA polymerase II occupancy reveals temporal activation of distinct metabolic pathways and changes in RXR dimer composition during adipogenesis. Genes Dev 22: 2953-2967. doi:10 $.1101 / \mathrm{gad} .501108$

Pertea M, Kim D, Pertea GM, Leek JT, Salzberg SL. 2016. Transcript-level expression analysis of RNA-seq experiments with HISAT, StringTie and Ballgown. Nat Protoc 11: 16501667. doi:10.1038/nprot.2016.095

Rayner KJ, Suarez Y, Davalos A, Parathath S, Fitzgerald ML, Tamehiro N, Fisher EA, Moore KJ, Fernandez-Hernando C. 2010. MiR-33 contributes to the regulation of cholesterol homeostasis. Science 328: 1570-1573. doi:10.1126/science .1189862

Rodeheffer MS, Birsoy K, Friedman JM. 2008. Identification of white adipocyte progenitor cells in vivo. Cell 135: 240-249. doi:10.1016/j.cell.2008.09.036

Rosen ED, MacDougald OA. 2006. Adipocyte differentiation from the inside out. Nat Rev Mol Cell Biol 7: 885-896. doi: $10.1038 / \mathrm{nrm} 2066$

Tang W, Zeve D, Suh JM, Bosnakovski D, Kyba M, Hammer RE, Tallquist MD, Graff JM. 2008. White fat progenitor cells reside in the adipose vasculature. Science 322: 583-586. doi:10.1126/ science. 1156232

Tontonoz P, Spiegelman BM. 2008. Fat and beyond: the diverse biology of PPAR $\gamma$. Annu Rev Biochem 77: 289-312. doi:10 .1146/annurev.biochem.77.061307.091829

Tontonoz P, Hu E, Spiegelman BM. 1994. Stimulation of adipogenesis in fibroblasts by PPAR $\gamma 2$, a lipid-activated transcription factor. Cell 79: 1147-1156. doi:10.1016/0092-8674(94) 90006-X

Vishvanath L, MacPherson KA, Hepler C, Wang QA, Shao M, Spurgin SB, Wang MY, Kusminski CM, Morley TS, Gupta RK. 2016. Pdgfr $\beta+$ mural preadipocytes contribute to adipocyte hyperplasia induced by high-fat-diet feeding and prolonged cold exposure in adult mice. Cell Metab 23: 350-359. doi:10.1016/j.cmet.2015.10.018

Wang H, Yang H, Shivalila CS, Dawlaty MM, Cheng AW, Zhang F, Jaenisch R. 2013a. One-step generation of mice carrying mutations in multiple genes by CRISPR/Cas-mediated genome engineering. Cell 153: 910-918. doi:10.1016/j.cell .2013 .04 .025

Wang QA, Tao C, Gupta RK, Scherer PE. 2013b. Tracking adipogenesis during white adipose tissue development, expansion and regeneration. Nat Med 19: 1338-1344. doi:10.1038/nm .3324

Wang QA, Tao C, Jiang L, Shao M, Ye R, Zhu Y, Gordillo R, Ali A, Lian Y, Holland WL, et al. 2015. Distinct regulatory mechanisms governing embryonic versus adult adipocyte maturation. Nat Cell Biol 17: 1099-1111. doi:10.1038/ncb3217

Wendling O, Bornert JM, Chambon P, Metzger D. 2009. Efficient temporally-controlled targeted mutagenesis in smooth muscle cells of the adult mouse. Genesis 47: 14-18. doi:10.1002/ dvg.20448

Wu Z, Rosen ED, Brun R, Hauser S, Adelmant G, Troy AE, McKeon C, Darlington GJ, Spiegelman BM. 1999. Cross-regulation of $\mathrm{C} / \mathrm{EBP} \alpha$ and $\mathrm{PPAR} \gamma$ controls the transcriptional pathway of adipogenesis and insulin sensitivity. Mol Cell 3: 151158. doi:10.1016/S1097-2765(00)80306-8

Ying W, Riopel M, Bandyopadhyay G, Dong Y, Birmingham A, Seo JB, Ofrecio JM, Wollam J, Hernandez-Carretero A, Fu W, et al. 2017. Adipose tissue macrophage-derived exosomal miRNAs can modulate in vivo and in vitro insulin sensitivity. Cell 171: 372-384.e12. doi:10.1016/j.cell.2017.08.035

Zeitels LR, Acharya A, Shi G, Chivukula D, Chivukula RR, Anandam JL, Abdelnaby AA, Balch GC, Mansour JC, Yopp AC, et al. 2014. Tumor suppression by miR-26 overrides potential oncogenic activity in intestinal tumorigenesis. Genes Dev 28: 2585-2590. doi:10.1101/gad.250951.114

Zeve D, Seo J, Suh JM, Stenesen D, Tang W, Berglund ED, Wan Y, Williams LJ, Lim A, Martinez MJ, et al. 2012. Wnt signaling activation in adipose progenitors promotes insulin-independent muscle glucose uptake. Cell Metab 15: 492-504. doi:10 .1016/j.cmet.2012.03.010

Zhao J, Wei J, Mialki RK, Mallampalli DF, Chen BB, Coon T, Zou C, Mallampalli RK, Zhao Y. 2012. F-box protein FBXL19-mediated ubiquitination and degradation of the receptor for IL-33 limits pulmonary inflammation. Nat Immunol 13: 651-658. doi:10.1038/ni.2341

Zhao J, Mialki RK, Wei J, Coon TA, Zou C, Chen BB, Mallampalli RK, Zhao Y. 2013. SCF E3 ligase F-box protein complex $\mathrm{SCF}^{\mathrm{FBXL19}}$ regulates cell migration by mediating Rac1 ubiquitination and degradation. FASEB I 27: 2611-2619. doi:10 $.1096 /$ fj.12-223099 


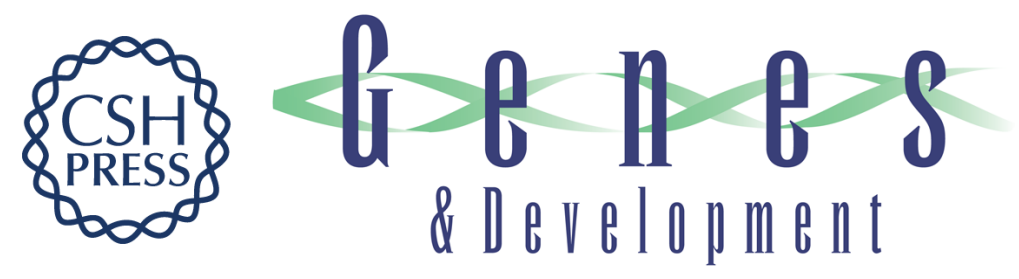

\title{
miR-26 suppresses adipocyte progenitor differentiation and fat production by targeting Fbx/19
}

\author{
Asha Acharya, Daniel C. Berry, He Zhang, et al.
}

Genes Dev. 2019, 33: originally published online September 5, 2019

Access the most recent version at doi:10.1101/gad.328955.119

\section{Supplemental http://genesdev.cshlp.org/content/suppl/2019/09/04/gad.328955.119.DC1 Material}

References This article cites 59 articles, 15 of which can be accessed free at: http://genesdev.cshlp.org/content/33/19-20/1367.full.html\#ref-list-1

Creative This article is distributed exclusively by Cold Spring Harbor Laboratory Press for the first Commons six months after the full-issue publication date (see

License http://genesdev.cshlp.org/site/misc/terms.xhtml). After six months, it is available under a Creative Commons License (Attribution-NonCommercial 4.0 International), as described at http://creativecommons.org/licenses/by-nc/4.0/.

Email Alerting Receive free email alerts when new articles cite this article - sign up in the box at the top Service right corner of the article or click here.

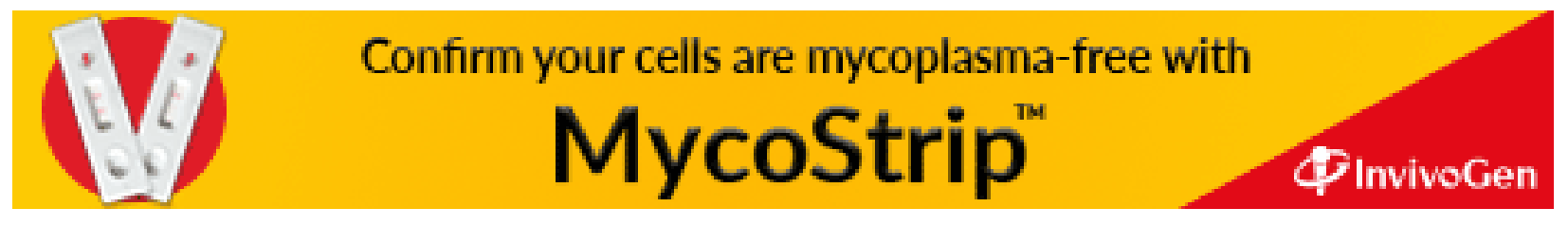

